\title{
19. PRELIMINARY ORGANIC GEOCHEMICAL ANALYSES OF THE CARIACO TRENCH SITE 147 DEEP SEA DRILLING PROJECT, LEG $15^{1}$
}

\author{
Bernd R. Simoneit, W. Glenn Howells and A. L. Burlingame, ${ }^{2}$ Space Sciences Laboratory, University of California, Berkeley
}

\begin{abstract}
Samples from Site 147, the organic geochemical site in the Cariaco Trench drilled during DSDP Leg 15 in the Caribbean Sea, were analyzed. The three samples, chosen from depths of 6 meters, 67 meters, and 138 meters, are all of Pleistocene age and were sedimented under essentially tropical climatic and anoxic conditions. The cores contain approximately 2.5 per cent organic carbon, approximately 25 per cent carbonate, and a high proportion of clay.

The solvent soluble organic material consists mainly of hydrocarbons and minor amounts of fatty acids and steroidal compounds. The principal hydrocarbon components of the 6-meter sample ( $10^{4}$ y B.P.) are isomers of norphytene and phytadiene which have been found in zooplankton and Black Sea cores. The alkanes, $\mathrm{C}_{n} \mathrm{H}_{2 n+2}$, ranged in all three samples from $n=18$ to $n=33$ with odd values predominating. The corresponding alkenes, $\mathrm{C}_{n} \mathrm{H}_{2 n}$, were detected in smaller amounts over a similar range and decreased in concentration with sample age.

Fatty acids in the sediments were isolated as the methyl esters. The formation of these esters, resulting from use of methanol as a component of the extraction solvent, was catalyzed by the clay minerals in the samples. The major constituent in each instance was methyl palmitate with minor amounts of methyl myristate and methyl stearate. Homologs above $\mathrm{C}_{20}$ were present in trace amounts.

Steroidal compounds such as cholesterol, ergosterol, $\beta$-sitosterol, cholestane, and stigmastane were found in all three samples. The sterols were more abundant in the 6-meter sample with a reductive diagenetic trend indicated for increasing age, i.e., 67 meters 130,000 y B.P. and 138 meters 270,000 y B.P. Minor amounts of triterpenoidal compounds were found in the two older samples. Their presence and the second maximum at about $\mathrm{C}_{29}$ in the alkane distribution indicate some influx of higher plant material into the trench. The anoxic marine environment has enhanced the preservation of this organic matter, allowing the identification of rather labile biochemical markers.
\end{abstract}

\section{INTRODUCTION}

On Leg 15 of the Deep Sea Drilling Project a hole was drilled at Site 147 especially for organic geochemical analysis. This site is in the Cariaco Trench $\left(10^{\circ} 42.68^{\prime} \mathrm{N}\right.$, $\left.65^{\circ} 10.45^{\prime} \mathrm{W}\right)$ at a water depth of 892 meters. This trench, on the continental shelf of Venezuela, is surrounded by water less than 200 meters deep and is divided into two flat basins separated by a saddle. The drilling site is on the gentle northern slope of the saddle. The cores consist almost throughout of dark olive green calcareous clay with

\footnotetext{
${ }^{1}$ Research supported by the Oceanographic Section, National Science Foundation NSF Grant GA-24214.

${ }^{2}$ John Simon Guggenheim Memorial Fellow, 1970-1972.
}

high organic content (Edgar et al., 1971). The penetration was 198 meters below the sea bed, all in the Pleistocene.

We report here preliminary results from three large samples which were selected from the recovered cores for analysis. They were chosen such that any obvious diagenetic changes in the organic matter could be assessed. The youngest sample is from the 6-meter level (147B-1-4), with an estimated sedimentation date of about $10^{4}$ y B.P.; the middle sample is from the 67-meter level (147B-7-4), estimated to have been deposited about 130,000 y B.P.; and the oldest sample is from the 138-meter level $\left(147 \mathrm{C}-3-1^{+}\right)$, deposited about 270,000 y B.P. These ages are based on the sedimentation rate of approximately $50 \mathrm{~cm} / 10^{3}$ y (Edgar et al., 1971). Of the thirteen samples obtained by this laboratory from Site 147, the three chosen were those having the highest organic carbon contents. 
The bottom waters in the Cariaco Trench are at present anoxic (Richards and Vaccaro, 1956). The absence of benthonic foraminifera in the upper part of the section indicates that these sediments were laid down partly under anaerobic conditions (Edgar et al., 1971). The climatic conditions throughout this sedimentary time span $(270,000$ y) were tropical. Since the sedimentation conditions in the Cariaco Trench are analogous to those in the Black Sea, a correlation will be made here with the organic analyses of selected Black Sea cores (Simoneit, in press).

\section{EXPERIMENTAL METHODS}

High resolution mass spectrometric analyses of the benzene/methanol and heptane soluble extracts were carried out on a GEC-AEI MS-902 mass spectrometer on-line with an XDS Sigma 7 computer (described by Burlingame, 1970, and Burlingame et al., 1970). The samples were introduced via a ceramic direct inlet probe into the ion source, operated at the following conditions: resolution 10,000 to 12,000 ; ionizing current $500 \mu \mathrm{A}$; ionizing voltage $50 \mathrm{eV}$; and temperature 200 to $220^{\circ} \mathrm{C}$. The scan rate was 16 seconds per decade with a clock rate of $24 \mathrm{kHz}$. Multiple scans were taken during each analysis and then sum averaged together during data reduction. Selected high resolution mass spectral data are presented as heteroatomic plots (Burlingame and Smith, 1968) in various figures in the text.

Gas chromatographic analyses were carried out using a Perkin-Elmer Model 900 gas chromatograph fitted with a flame ionization detector and operating under the conditions stated in the respective figure legends. Analyses using gas chromatography-mass spectrometry were carried out on a modified Perkin-Elmer Model $270 \mathrm{GC} / \mathrm{MS}$ linked on-line to an XDS Sigma 2 computer (Smith et al., 1971). The GC conditions used in the GC/MS analyses are cited in the respective figure legends, and the mass spectrometric and computer operating parameters are as reported (Smith et al., 1971).

Infrared spectra were obtained using a Perkin Elmer Model 257 infrared spectrophotometer fitted with a beam condenser. The spectra of the samples were obtained as thin films between $\mathrm{KBr}$ plates. The chloroform was removed from the samples (determined by absence of $\mathrm{CHCl}_{3}$ absorption at $1200 \mathrm{~cm}^{-1}$ and $700-800 \mathrm{~cm}^{-1}$ ) by heating at $60^{\circ} \mathrm{C}$ and $25 \mathrm{~cm} \mathrm{Hg}$ pressure prior to analysis.

All solvents used, e.g., benzene, methanol, and $n$-heptane were Matheson Coleman and Bell Pesticide quality and/or Mallinckrodt Nanograde quality. Benzene and methanol were redistilled in an all glass apparatus prior to use.

\section{Extraction of Sample 147B-1-4 (6 m Below Sea Bed)}

The schematic of the following separation procedure is shown in Figure 1. A core sample (wet weight $683.8 \mathrm{~g}$ ) was sonicated with distilled water $(400 \mathrm{ml})$ for 30 minutes and the resulting finely dispersed clay filtered under suction. This procedure was repeated and the combined aqueous filtrates stored under refrigeration for future studies. The filter cake was subdivided and dried $\left(60^{\circ} \mathrm{C}\right.$ and $25 \mathrm{~cm} \mathrm{Hg}$ pressure) and then finely powdered (100-200 mesh) in a Pitchford ball mill, yielding 354.8 grams of dry powder. Using a 3:1 mixture of benzene and methanol the powder

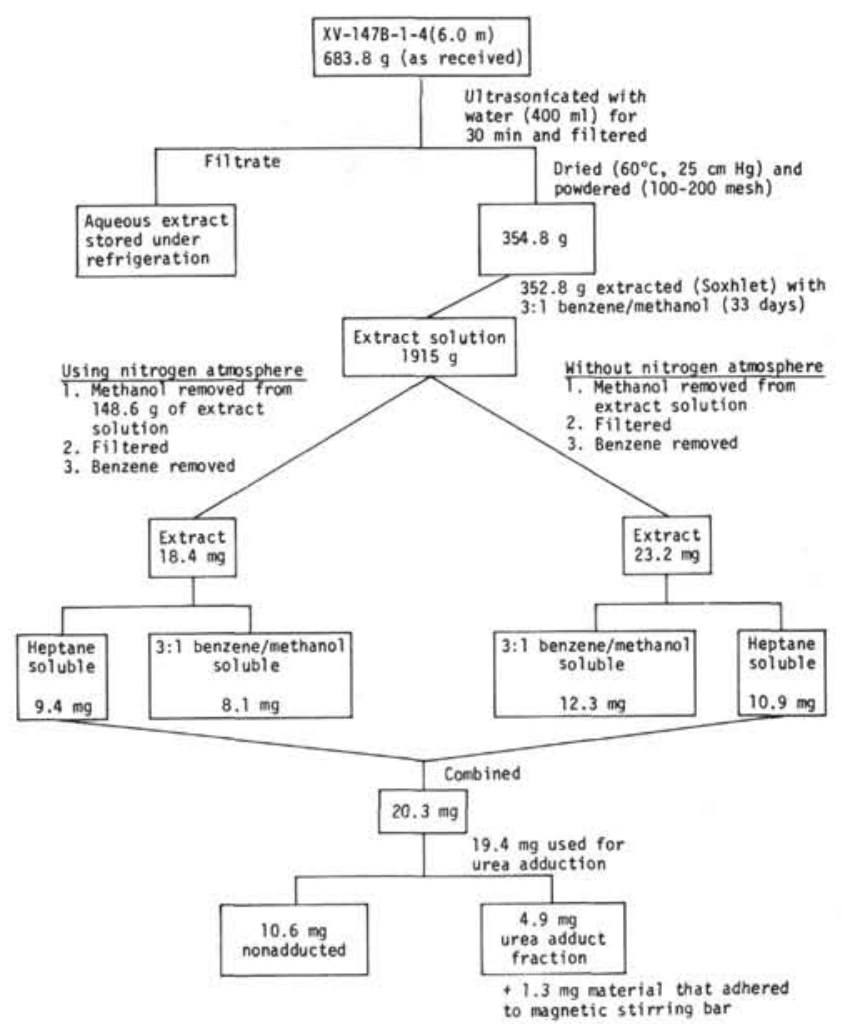

Figure 1. Schematic of the separation procedure and yields for Sample 147B-1-4 (6 m below sea bed).

$(352.8 \mathrm{~g})$ was extracted in a Soxhlet apparatus for thirtythree days; the extraction was then visually judged to be complete. The total benzene/methanol extract solution weighed 1915 grams.

An aliquot (148.6 g) of benzene/methanol extract solution was withdrawn and, operating under a nitrogen atmosphere, the methanol was gradually replaced by benzene using a rotary evaporator. The benzene solution was suction filtered under nitrogen to remove material that had precipitated during evaporation of the methanol. The filtered solid was washed with diethyl ether and solvent removed from the filtrate to give $18.4 \mathrm{mg}$ of total extract (GC trace Figure 2a). On the basis of dry powdered core material the extractable organic content is 0.08 per cent. This extract $(18.4 \mathrm{mg})$ was dissolved in benzene $(0.5 \mathrm{ml})$ and slowly added with stirring to $n$-heptane $(120 \mathrm{ml})$. The major portion of the solvent mixture was removed using a rotary evaporator which azeotropically distilled out the benzene (benzene/heptane azeotrope composition99.3/0.7) and the mixture was then filtered. Removal of heptane from the filtrate gave $9.4 \mathrm{mg}$ of material (GC trace Figure 2c). The green colored filtered solid was dissolved in a 3:1 mixture of benzene/methanol. Solvent removal gave $8.1 \mathrm{mg}$ of material ( $\mathrm{GC}$ trace in Figure 2e).

A further aliquot of the total benzene/methanol extract solution (original weight $1915 \mathrm{~g}-\mathrm{cf}$. above) was removed and taken through the same sequence of steps given above (Figure 1). In this instance an inert nitrogen atmosphere was not used. This afforded $23.2 \mathrm{mg}$ of total extract (GC trace Figure $2 \mathrm{~b}$ ) which when divided into heptane soluble and $3: 1$ benzene/methanol soluble portions gave $10.9 \mathrm{mg}$ 


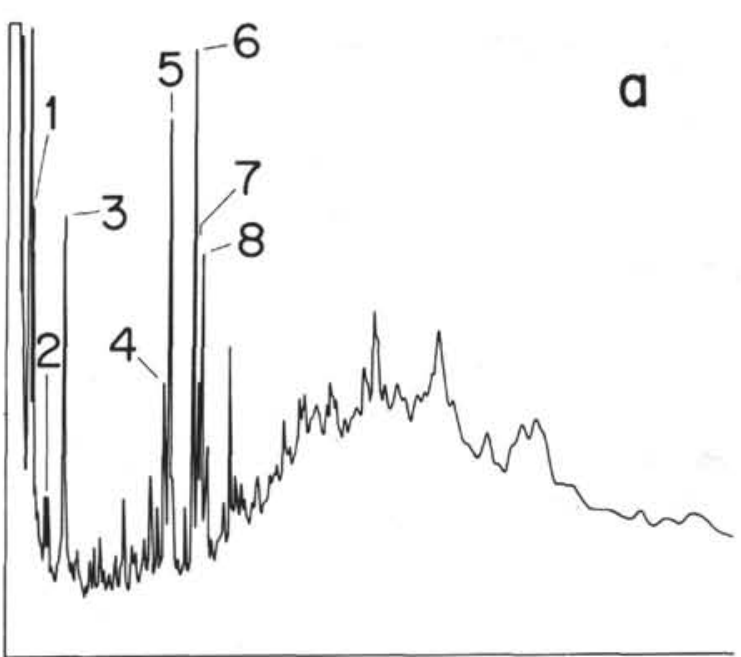

Time $\longrightarrow$

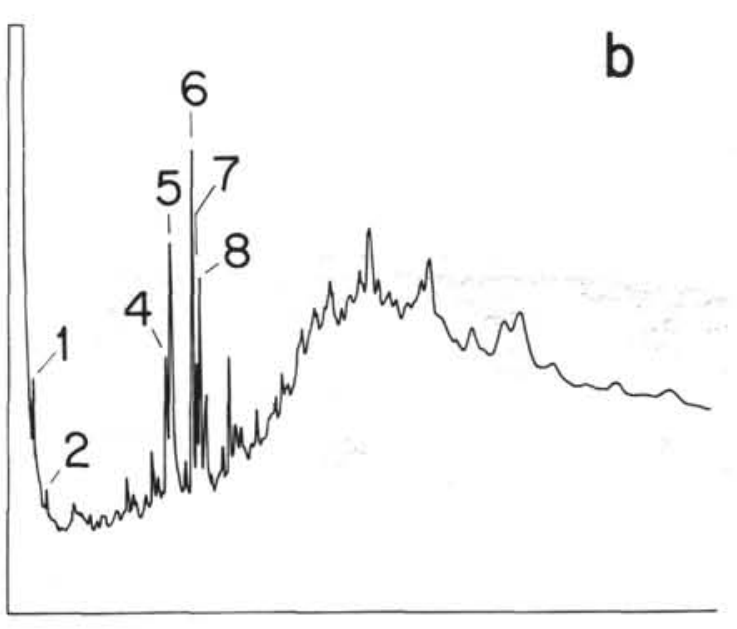

Time $\longrightarrow$

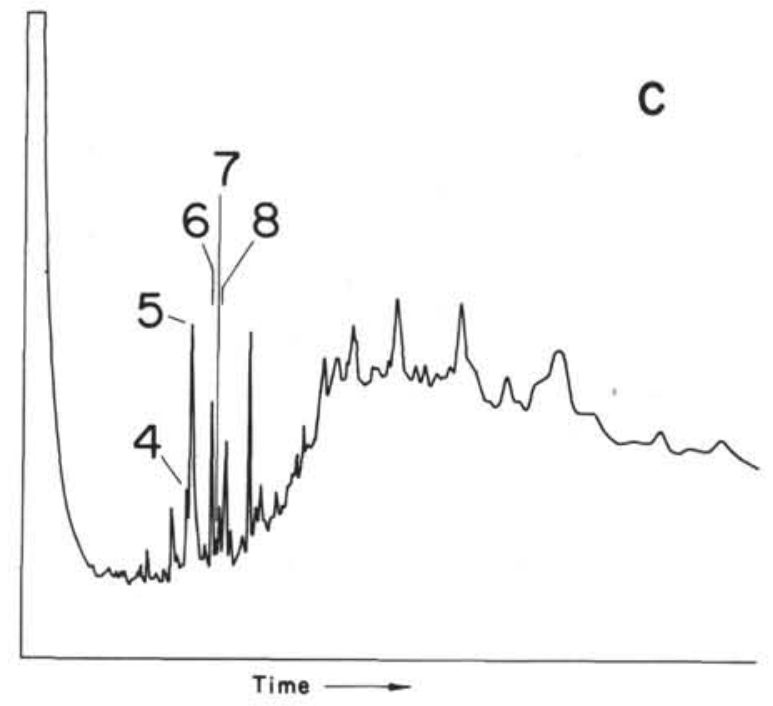

Time

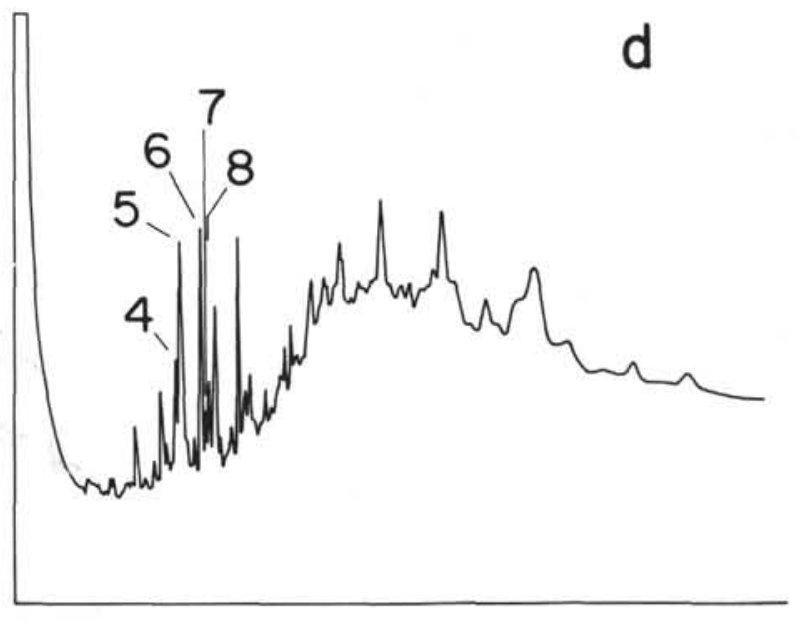

Time -

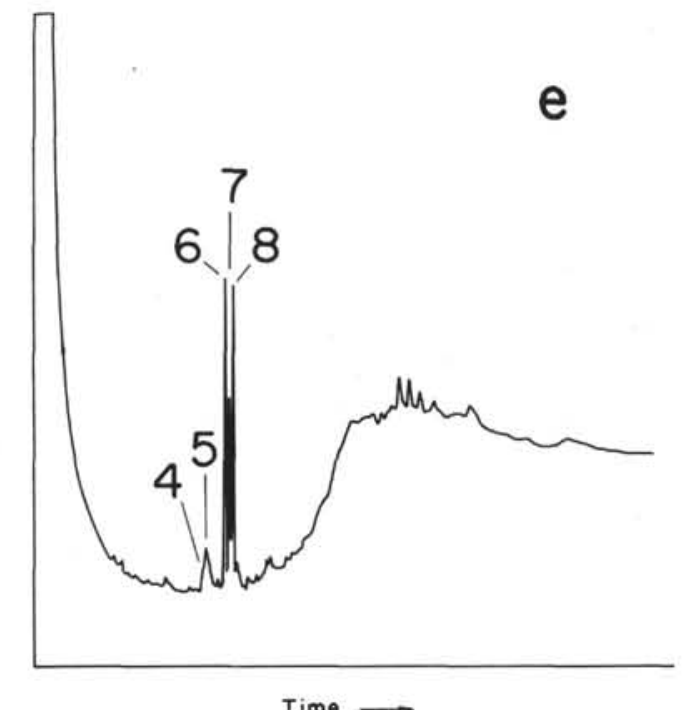

Time $\longrightarrow$

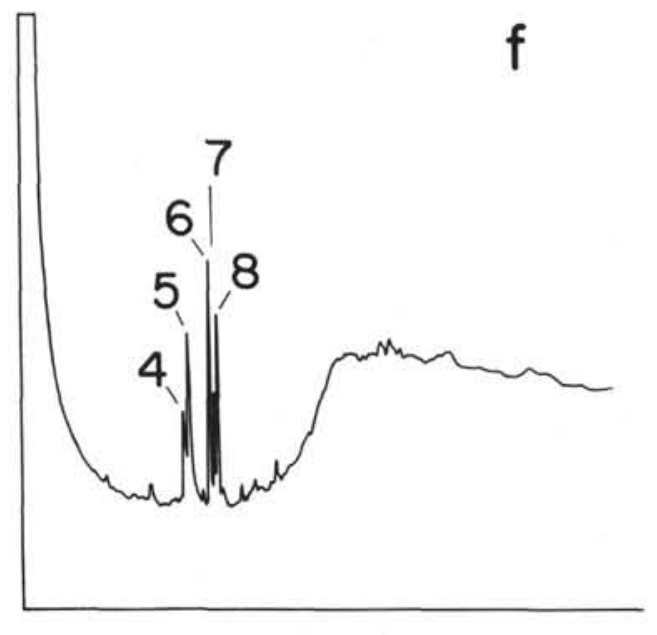

Time $\longrightarrow$

Figure 2. Gas liquid chromatograms of the extracts from the Sample 147B-1-4 (6 m below sea bed). (a) Total extract obtained using a nitrogen atmosphere (3.4 $\mathrm{\mu l}$ of $3.4 \mathrm{wt} \%$ solution in benzene); (b) Total extract (2.0 $\mathrm{l} 1$ of $2.0 \mathrm{wt} \%$ solution in benzene); (c) Heptane soluble fraction obtained using a nitrogen atmosphere $(1.0 \mu 1$ of $4.5 \mathrm{wt} \%$ solution in $3: 1$ benzene/methanol); (d) Heptane soluble fraction $(1.0 \mu 1$ of 4.5 wt \% solution in 3:1 benzene/methanol); (e) Benzene/methanol soluble fraction obtained using a nitrogen atmosphere (1.1 11 of $3.1 \%$ solution in 3:1 benzene/methanol); (f) Benzene/methanol soluble fraction (1.8 $\mu 1$ of $3.6 \mathrm{wt} \%$ solution in $3: 1$ benzene/methanol); GC conditions: $10 \mathrm{ft}$. $\times 1 / 8$ in. stainless steel column, packed with $3 \%$ OV-1 on gaschrom $Q$, programmed from $100-275^{\circ} \mathrm{C}$ at $8^{\circ} / \mathrm{min}$ and using $\mathrm{He}$ at $60 \mathrm{ml} / \mathrm{min}$. 
and $12.3 \mathrm{mg}$ respectively (GC traces Figures $2 \mathrm{~d}$ and f). As may be seen by comparing the appropriate GC traces (Figure 2a, c, e vs. 2b, d, f) the products obtained in the nitrogen-blanketed and non-nitrogen-blanketed experiments are essentially equivalent. Accordingly, the heptane soluble fractions were combined.

Heptane soluble material ( $19.4 \mathrm{mg}$ ) dissolved in benzene $(0.25 \mathrm{ml})$ was added dropwise to a boiling solution of urea $(0.63 \mathrm{~g})$ in methanol $(2 \mathrm{ml})$ to which 1 drop each of $n$-heptane and $n$-decane had previously been added. The stirred mixture was refluxed for $1 \mathrm{hr}$, allowed to gradually cool and then stirred overnight at room temperature. Solvent was removed on a rotary evaporator without heating and the product transferred to a filter and washed with ice cold $n$-heptane $(4 \times 1 \mathrm{ml})$. The filtrate on concentration gave $10.6 \mathrm{mg}$ of nonadducted material. Additionally, material $(1.3 \mathrm{mg})$ adhering to the magnetic stirring bar was obtained by washing with benzene/methanol and water followed by the azeotropic removal of methanol and water with benzene. The solid urea adduct was decomposed with water and the aqueous phase exhaustively extracted with ether. The ether phase was washed with saturated aqueous magnesium sulfate and then with water. Removal of ether and use of benzene for azeotropic removal of water (rotary evaporator) furnished $4.9 \mathrm{mg}$ of urea adducted material.

\section{Extraction of Sample 147B-7-4 (67 m Below Sea Bed)}

The schematic of the following separation procedure is shown in Figure 3. The wet sample $(1191 \mathrm{~g})$ was twice sequentially sonicated $(30 \mathrm{~min})$ with distilled water $(1500 \mathrm{ml})$ and filtered. The aqueous filtrates were combined and refrigerated in readiness for future studies. Division of the filter cake, drying and powdering gave 768.1 grams of material. A portion of the powder $(36.7 \mathrm{~g})$ was mixed with 59.7 grams of washed and ignited Ottawa sand (60 mesh) that had previously been sonicated twice with benzene and methanol $(3: 1)$.

This mixture of significantly higher permeability was extracted (Soxhlet) with $3: 1$ benzene/methanol for four days at which time extraction was visually judged to be complete.

The benzene/methanol extract solution was worked up without using nitrogen as described above to give $26.9 \mathrm{mg}$ of total extract corresponding to a yield (based on dry powder) of 0.07 per cent extractable organic material. This extract $(25.8 \mathrm{mg})$ was separated in the manner described above to give $15.1 \mathrm{mg}$ of heptane soluble material and $9.5 \mathrm{mg}$ of benzene/methanol soluble material. The heptane soluble portion $(14.5 \mathrm{mg})$ on treatment with urea (cf. above) gave $2.5 \mathrm{mg}$ of an adducted fraction and $9.6 \mathrm{mg}$ of a nonadducted fraction.

\section{Extraction of Sample 147C-3-1 ${ }^{+}$(138 m Below Sea Bed)}

The schematic of the following separation procedure is shown in Figure 4. This material was received in the core tube fitted with end caps. The caps were removed and $1 / 8$ to $1 / 4^{\prime \prime}$ of the sample, which had been in contact with each of the caps, was discarded. The main portion of the sample was extruded from the tube to give 1596 grams (wet weight) of material which was divided into six approximately equal batches. Each sample required extensive

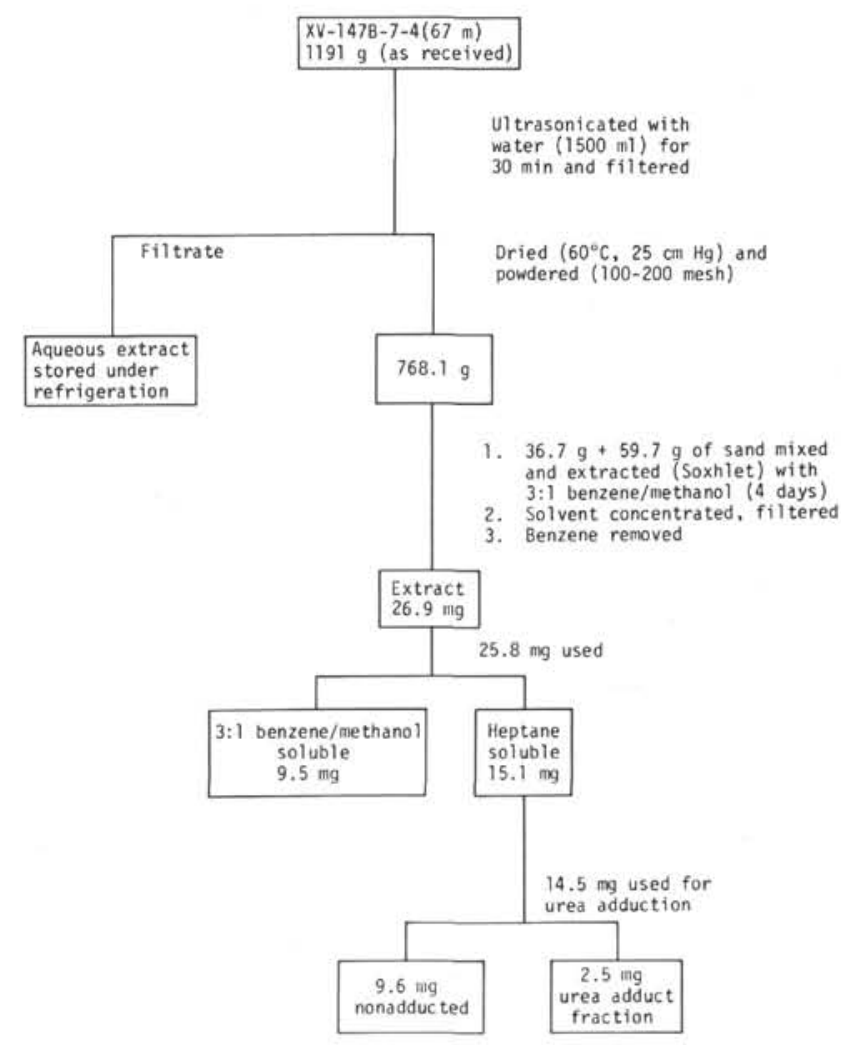

Figure 3. Schematic of the separation procedure and yields for Sample 147B-7-4 (67 m below sea bed).

mechanical division and 90 minutes of sonication with distilled water $(125 \mathrm{ml})$ before suitable deaggregation occurred. The material was filtered and for each batch sonication (30 $\mathrm{min})$ was repeated with distilled water $(125 \mathrm{ml})$. The combined aqueous filtrates were stored under refrigeration for future studies. The filter cake after appropriate subdivision, drying, and milling (cf. above) provided 1023 grams of dry powder. A 3:1 mixture of benzene/methanol was used to extract (Soxhlet) 960.7 grams of powdered sample. (In this instance the Soxhlet thimbles were half filled with solvent prior to addition of power and in this way complete wetting of the sample was achieved before extraction was started.) The extraction was visually judged to be complete in 22 days and a total benzene/methanol extract solution of 2818 grams was obtained.

An aliquot $(276.6 \mathrm{~g})$ of the benzene/methanol extract solution was withdrawn and taken through the procedure detailed above except that nitrogen was not used (Figure 4). This initially furnished $100.8 \mathrm{mg}$ of total extract corresponding to an extractable organic content (based on dry powder) of 0.11 per cent. A portion of the extract (100.2 mg) was divided into a heptane soluble fraction (51.7 mg) and a benzene/methanol soluble fraction $(35.0 \mathrm{mg})$. The heptane soluble portion (47.2 mg) was subjected to urea adduction (cf. above), yielding $14.4 \mathrm{mg}$ of urea adducted and $27.7 \mathrm{mg}$ of nonadducted materials.

In summary, the overall yields for the three samples are shown in Table I. 


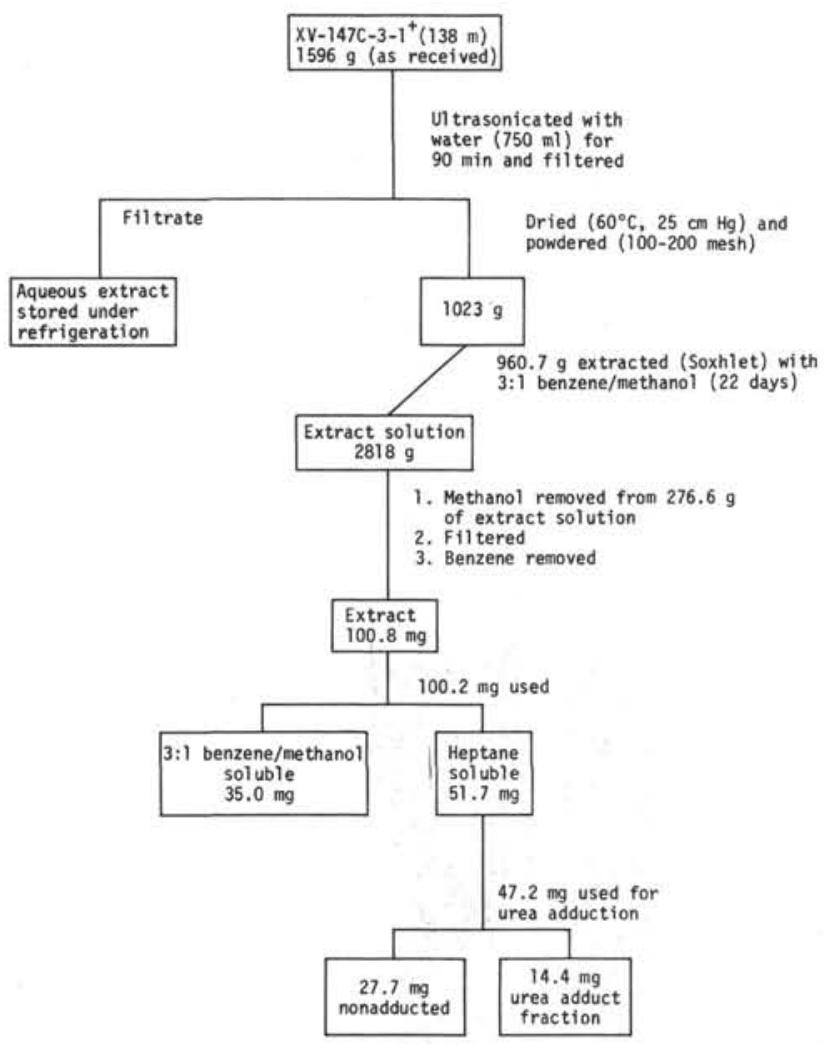

Figure 4. Schematic of the separation procedure and yields for Sample 147C-3-1+ $(138 \mathrm{~m}$ below sea bed $)$.

TABLE 1

Extraction Yield Summary for the Site 147 Samples

\begin{tabular}{|c|c|c|c|c|}
\hline & \multicolumn{4}{|c|}{ Sample } \\
\hline & $6 \mathrm{~m}$ & $67 \mathrm{~m}$ & $138 \mathrm{~m}$ & Mean \\
\hline Net weight & $648 \mathrm{~g}$ & $1191 \mathrm{~g}$ & $1596 \mathrm{~g}$ & - \\
\hline $\begin{array}{l}\text { Dry weight (after sonica- } \\
\text { tion with water, filtration } \\
\text { and drying) }\end{array}$ & $355 \mathrm{~g}$ & $768 \mathrm{~g}$ & $1023 \mathrm{~g}$ & - \\
\hline $\begin{array}{l}\text { Water and water soluble } \\
\text { materials (based on origi- } \\
\text { nal sample) }\end{array}$ & $48 \%$ & $36 \%$ & $36 \%$ & - \\
\hline $\begin{array}{l}\text { Organic solvent extracta- } \\
\text { ble fraction (of dried } \\
\text { material following } \\
\text { aqueous extraction) }\end{array}$ & $0.08 \%$ & $0.07 \%$ & $0.11 \%$ & - \\
\hline $\begin{array}{l}\text { Total organic extract } \\
\text { estimated weight (based } \\
\text { on aliquot amount }\end{array}$ & $0.284 \mathrm{~g}$ & $0.538 \mathrm{~g}$ & $1.123 \mathrm{~g}$ & - \\
\hline $\begin{array}{l}\mathrm{HC1} \text { soluble (based on } \\
\text { original sample) }\end{array}$ & $17 \%$ & $21 \%$ & $22 \%$ & - \\
\hline $\begin{array}{l}\text { Benzene/methanol ( } 3: 1) \\
\text { soluble fraction (based } \\
\text { on total organic extract) }\end{array}$ & $46 \%{ }^{a}$ & $39 \%{ }^{a}$ & $40 \%{ }^{a}$ & $42 \% a$ \\
\hline $\begin{array}{l}\text { Normal fraction, heptane } \\
\text { soluble (based on total } \\
\text { organic extract) }\end{array}$ & $17 \%^{a}$ & $13 \% \mathrm{a}$ & $20 \%$ a & $17 \%^{\mathrm{a}}$ \\
\hline $\begin{array}{l}\text { Branched/cyclic fraction, } \\
\text { heptane soluble (based } \\
\text { on total organic } \\
\text { extract) }\end{array}$ & $37 \% \mathrm{a}$ & $48 \%^{a}$ & $40 \% a$ & $42 \% a$ \\
\hline
\end{tabular}

aData normalized.

\section{Aqueous Extracts}

Aliquots $(3 \mathrm{ml})$ of each of the aqueous extracts from the 6 meter, 67 meter, and 138 meter samples were azeotroped with toluene to remove water. To each sample was added $40 \mu \mathrm{l}$ of Tri-Sil/BSA and $10 \mu \mathrm{l}$ of trimethylchlorosilane. After allowing the mixtures to stand for 30 to 45 minutes, $5 \mu \mathrm{l}$ samples were injected onto a $10^{\prime} \times 1 / 8^{\prime \prime}$ stainless steel column containing 3 per cent $\mathrm{OV}-1$ on Chromosorb W. The temperature was programmed from 100 to $275^{\circ} \mathrm{C}$ at $8^{\circ} \mathrm{C} / \mathrm{min}$ with a helium carrier gas flow rate of $40 \mathrm{ml} / \mathrm{min}$. The GC traces of the three samples were identical to each other and to the $\mathrm{GC}$ obtained on a $3 \mathrm{ml}$ sample of distilled water which had been subjected to an identical procedure.

\section{RESULTS}

Since the deposition occurring in the Cariaco Trench took place under partially anoxic conditions it was decided to prepare a portion of the 6-meter extract material under a nitrogen atmosphere. Using such an inert atmosphere it was hoped that any possible oxidative changes would be minimized. Furthermore, this sample was chosen over the 67-meter and 138-meter materials because it was expected that this recent sediment would contain the most labile organic components.

A GC trace of the total extract of the 6-meter sample is shown in Figure 2a. Operating under a nitrogen atmosphere, this total extract was divided into a heptane soluble fraction (Figure 2c) and a benzene/methanol soluble fraction (Figure 2e). The GC traces indicate that with reference to peaks 4 to 8 an almost complete separation has taken place of peaks 6 to 8 which are concentrated in the benzene/methanol fraction (Figure 2e). The total extract composite peaks labeled 1 to 3 in Figure 2a are absent, however, in the derived materials (Figure $2 \mathrm{c}$ and e). This implies either that the components responsible for peaks 1 to 3 in Figure 2a are extremely volatile and were lost during the separation procedure or that they underwent decomposition during separation.

Another aliquot of the 6-meter extract solution was prepared and separated without the nitrogen atmosphere. The total extract (Figure 2b) was again divided into heptane and benzene/methanol soluble portions (Figures $2 \mathrm{~d}$ and $f$, respectively). In Figure $2 b$, peaks with the same retention times as peaks 1 and 2 of Figure 2a are significantly smaller and peak 3 is completely absent. More important, however, is the overall near identity of the GC traces in Figures $2 \mathrm{a}$ and $\mathrm{b}$. Also, when the total extract obtained without the use of nitrogen was divided into heptane (GC Figure 2d) and benzene/methanol (GC Figure 2f) soluble fractions, not only were peaks 1 to 3 absent, but with one exception noted below, the GC traces of Figure $2 \mathrm{~d}$ and $\mathrm{f}$ were extremely similar to those of Figures $2 \mathrm{c}$ and $\mathrm{e}$, respectively. The difference between Figures $2 \mathrm{e}$ and $\mathrm{f}$ lies in the dominance of peaks 6 to 8 in Figure $2 \mathrm{e}$ in relation to peaks 4 and 5 . Moreover in Figure $2 d$, peaks 4 and 5 are relatively more intense with respect to peaks 6 to 8 than in Figure 2c. This different distribution of peaks 4 to 8 is more likely to be a function of the exact mode of separation of the heptane and benzene/methanol fractions rather than being a result of using a nitrogen atmosphere. 
It was decided on the basis of these GC results that use of a nitrogen atmosphere was not warranted, at least for these preliminary studies, and that labile compounds possibly present in peaks 1 to 3 (Figure 2a) will have to be considered at a later date. It may be that since peaks 1 to 3 are absent in Figures $2 \mathrm{c}$ and $\mathrm{e}$, structure determination will necessarily have to be conducted on a total extract immediately after its isolation using a nitrogen atmosphere.

Infrared spectra of the total extracts and of the derived heptane and benzene/methanol soluble fractions were obtained for all three samples. The IR spectra are shown in Figure 5.

The spectra of the initial extract from each sample are extremely similar (Figures $5 \mathrm{a}$ to $\mathrm{c}$ ). The broad absorption bands in the region from about 3200 to $3500 \mathrm{~cm}^{-1}$ (with a minimum transmittance at $3400 \mathrm{~cm}^{-1}$ ) may be ascribed to the presence of any or all of the following functions: polymeric $\mathrm{OH} ;-\mathrm{OH}$ bonded to $>\mathrm{C}=0$, as in carboxylic acid dimers; $\pi$-bonded $-\mathrm{OH}$; and free and associated primary and secondary amines. The general absence of absorption in the region 3000 to $3100 \mathrm{~cm}^{-1}$ would appear to rule out the presence, in these particular samples, of substantial (i.e., $>5 \%$ ) amounts of aromatic compounds, but clearly considerable aliphatic C-H stretching absorption is present at 2840 to $2845 \mathrm{~cm}^{-1}$ and 2900 to $2920 \mathrm{~cm}^{-1}$. Bending (or deformation) vibrations for $\mathrm{C}-\mathrm{H}$ groups are also present at 1370 to $1380 \mathrm{~cm}^{-1}$ and 1450 to $1460 \mathrm{~cm}^{-1}$ while the $\left(\mathrm{CH}_{2}\right)_{n}$ rocking mode is present at $720 \mathrm{~cm}^{-1}$. The generally intense absorption in the region $1700 \pm 20 \mathrm{~cm}^{-1}$ may be indicative of a multiplicity of compound types containing the carbonyl function, such as acids, esters, and ketones.

These same results are the case for the IR spectra (Figures 5g, h, and i) of the benzene/methanol fractions. The band at $765 \mathrm{~cm}^{-1}$ in the spectrum shown in Figure $5 \mathrm{i}$ and to a lesser extent in Figure $5 \mathrm{~g}$ and $\mathrm{h}$ is possibly due to residual solvent (see experimental section). Evidently the strongly polar nature of the benzene/methanol fraction made it difficult to remove the final traces of chloroform.

In the IR spectra of the heptane soluble fractions (Figures 5d, e, and $\mathrm{f}$ ), the $\left(\mathrm{CH}_{2}\right)_{n}$ vibrational modes are enhanced with respect to those in the parent extracts. Very significant in the spectrum of the 138-meter heptane soluble fraction (Figure 5f) is the appearance of aromatic absorption at 2900 to $3000 \mathrm{~cm}^{-1}$ (C-H stretching) and 665 to $680 \mathrm{~cm}^{-1}$ (C-H out of plane bending).

The GC traces of the total extracts and benzene/ methanol soluble fractions of the 67-meter and 138-meter samples are shown in Figure 6. The GC traces of the total extracts (Figures 6a and b) indicate that many components are common to both samples, although the relative peak intensities differ. The GC traces of the heptane soluble fractions from the 6-meter, 67-meter, and 138-meter samples are shown in Figures 7a through c, respectively. Here again a similarity exists between materials from the three depths.

Following urea adduction to effect a separation of normal material from branched/cyclic components, gas liquid chromatography of the fractions gave the traces shown in Figure 8. The parallelism of the traces in Figures $8 \mathrm{a}$ through $\mathrm{c}$ (the normal fractions) is obvious. The GC traces of the branched/cyclic fractions (Figures 8d through f) exhibit a general similarity, but some peaks are unique to a particular fraction.

An attempt to obtain some preliminary results on possible organic components present in the aqueous extracts from the three samples was unsuccessful. Aliquots of the aqueous extracts were azeotroped with toluene to remove water and then trimethylsilylated. GC analysis of the products, however, gave traces that were identical to those obtained after conducting the same sequence of operations on a sample of distilled water. These results do not necessarily imply that there are no low molecular weight water soluble organic materials present in the aqueous extracts. Such materials might still be present, especially since the aqueous extracts are markedly yellow in color, but under the conditions used to remove water, they could have undergone polymerization or condensation to give compounds not convertible to volatile derivatives on trimethylsilylation. Gel permeation chromatography could be conducted on the original aqueous extracts without any concentration step and would very likely provide interesting data.

The elemental analyses for these Site 147 samples are given in Table 2. The analytical results obtained on the originally received total samples after drying indicate a decreasing nitrogen content and an increasing sulfur content with depth. The aqueous extracted and dried samples prior to $\mathrm{HC} 1$ treatment show an increase in carbon content with increasing depth and a parallel and substantial decreasing nitrogen content. This decrease in nitrogen content is not apparent in the samples after $\mathrm{HC} 1$ treatment. The carbon and hydrogen values do not exhibit any trends with increasing depth except following $\mathrm{HCl}$ treatment in which instance the hydrogen content decreases.

The normalized yield data for the various fractions, which are given in Table 1, deviate from the respective means of 42 per cent (benzene/methanol soluble) by \pm 4 per cent, 17 per cent (heptane - normal) by \pm 4 per cent and 42 per cent (heptane - branched/cyclic) by \pm 6 per cent. In general it can be said that the proportion of these fractions does not vary too greatly with depth.

The total benzene/methanol extracts and a heptane soluble fraction of the samples were analyzed by high resolution mass spectrometry. ${ }^{3}$ The data for the benzene/

\footnotetext{
${ }^{3}$ In this report, all high-resolution mass spectra are presented as heteroatomic plots (Burlingame and Smith, 1968) with the masses plotted in methylene units. On the abscissa, each principal division marker corresponds to the saturated alkyl fragment (even-electron ion), for example, $\mathrm{C}_{n} \mathrm{H}_{2 n+1}$, with the number of carbon and hydrogen atoms given subsequently. Each principal division of the abscissa is further divided into seven units. The number of hydrogen atoms of an unsaturated or cyclic-fragment ion is obtained by subtracting the number of units (two hydrogen atoms) or half-units from the $2 n+1$ hydrogen atoms of the respective saturated principal division, $\mathrm{C}_{n} \mathrm{H}_{2 n+1}$. Fragments with more than seven degrees of unsaturation are plotted with each principal division marker on the abscissa corresponding to the fragment ion $\mathrm{C}_{n} \mathrm{H}_{2 n-13}$. Each principal division is again further divided into seven units, and the number of hydrogen atoms of a fragment ion is derived as discussed above. Even more unsaturated ions are plotted with each principal division marker corresponding to compositions $\mathrm{C}_{n} \mathrm{H}_{2 n-27}$, etc. The origin of the abscissas is the same $\mathrm{m} / \mathrm{e}$ ratio for each plot, thus the nominal masses, indicated in 50 mass unit intervals below the carbon/hydrogen ratio scale, lie directly above one another from
} 

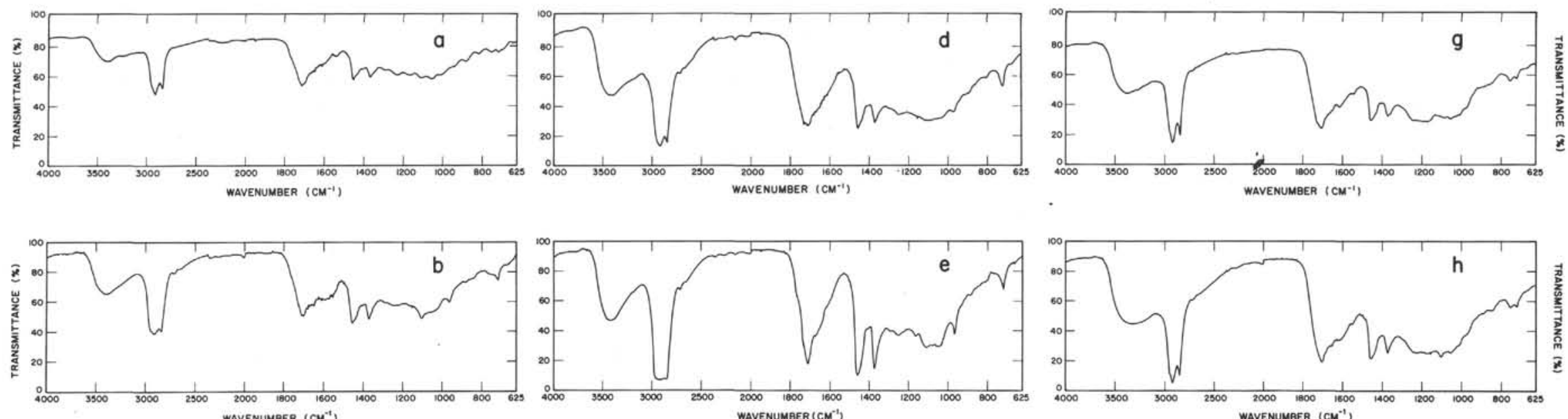

$$
\text { WAVENUMBER }\left(\mathrm{CM}^{-1}\right)
$$

WAVENUMBER (CM')'
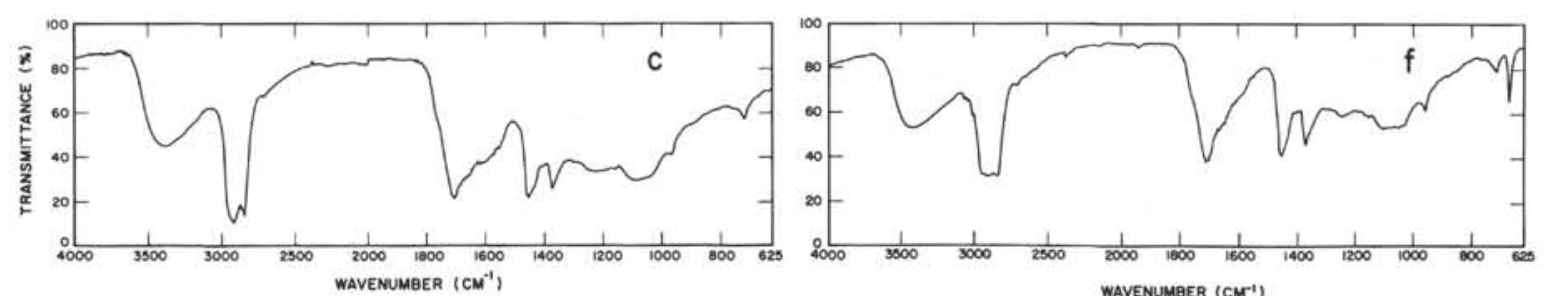

WAVENUMBER (CM-1).

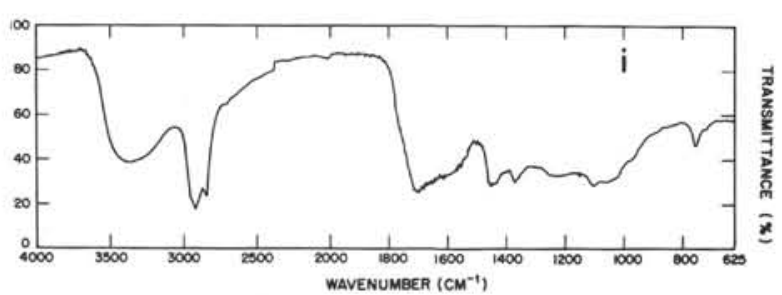

Figure 5. Infrared spectra of the following: (a) Total extract of 6-meter Sample 147B-1-4); (b) Total extract of 67-meter Sample 147B-7-4); (c) Total extract of 138-meter Sample 147C-3-1+); (d) Heptane soluble fraction of 6-meter sample; (e) Heptane soluble fraction of 67-meter sample; (f) Heptane soluble fraction of 138-meter sample; ( $\mathrm{g}$ ) Benzene/methanol soluble fraction of 6-meter sample; $(\mathrm{h})$ Benzene/methanol soluble fraction of 67-meter sample; (i) Benzene/methanol soluble fraction of 138-meter sample. 

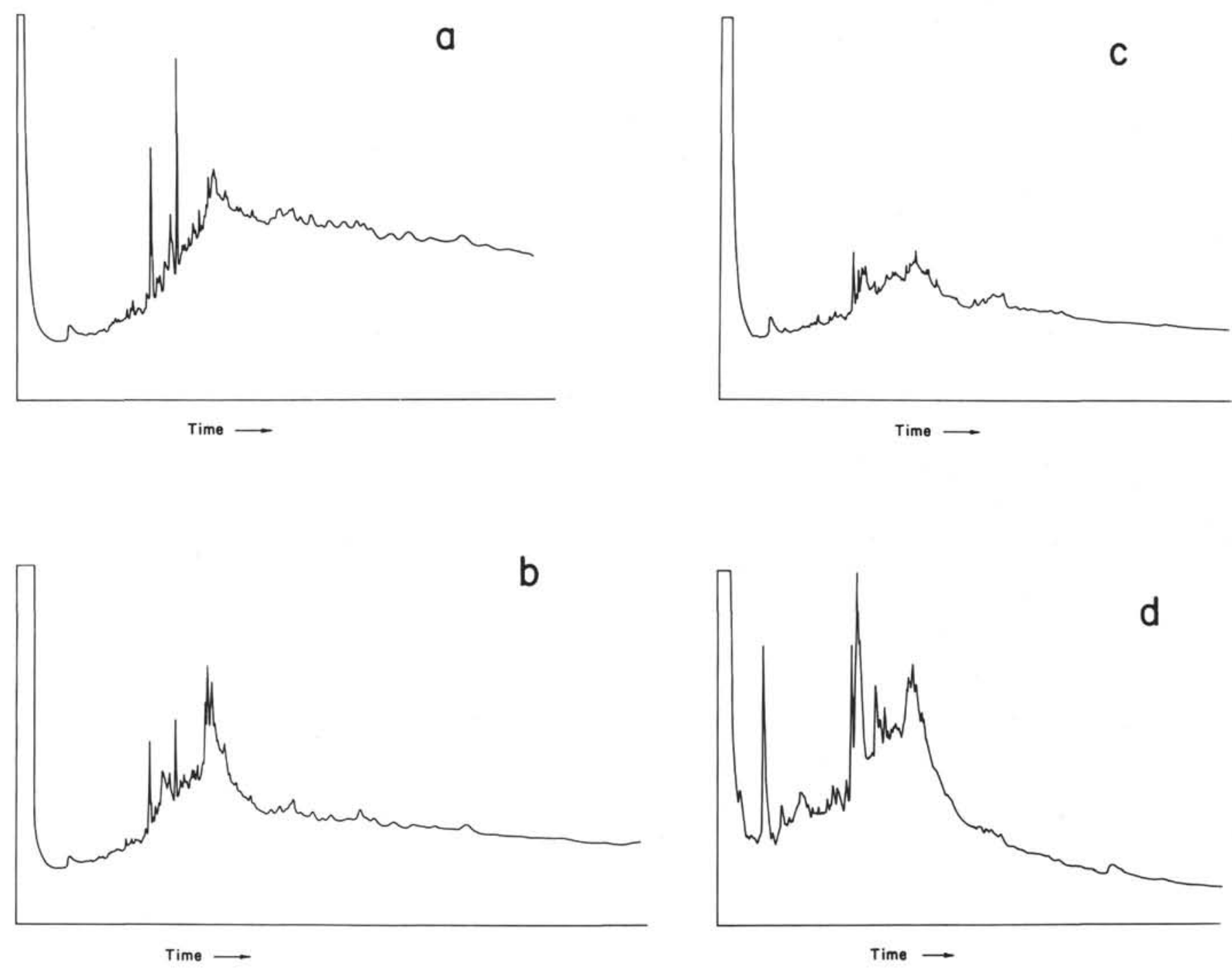

Figure 6. Gas liquid chromatograms of the following: (a) Total extract of the 67-meter sample $15.0 \mu 1$ of 7.0 wt \% solution in chloroform); (b) Total extract of the 138-meter sample $(5.0 \mu 1$ of 6.0 wt \% solution in chloroform); (c) Benzene/methanol soluble fraction of the 67-meter sample (4.1 $\mu 1$ of 20 wt \% solution in chloroform); (d) Benzene/methanol soluble fraction of the 138-meter sample ( $7.8 \mu 1$ of 24 wt \% solution in chloroform) GC conditions as cited in Figure 2, except He at $40 \mathrm{ml} / \mathrm{min}$.

plot to plot. All plots are normalized to a base peak (usually the base peak of the entire spectrum, unless otherwise specified) on the relative intensity scale. In order to make high mass, low intensity features of the spectrum observable, the whole spectrum or any region thereof can be multiplied by a scale factor. This factor is indicated by / $\mathrm{X} 00$ at the point of scale expansion.

methanol extract from Sample 147B-1-4 (from 6 meters depth) are shown in Figure 9 and the data for the heptane soluble fraction are shown in Figure 10. The major constituents apparent in Figure 9 are olefinic hydrocarbons, with phytadiene $\left(\mathrm{C}_{20} \mathrm{H}_{38}\right)$ and a $\mathrm{C}_{18}$ diene $\left(\mathrm{C}_{18} \mathrm{H}_{34}\right)$ as the major homologs. Alkanes, carboxylic acids or esters, and contaminants (phthalates and/or butyl esters) are not significant in this data. The heptane fraction (Figure 10) also consists mainly of olefinic hydrocarbons with significant amounts of steroidal and terpenoidal compounds. Of the olefins, phytadiene appears as a major constituent. The peaks of compositions $\mathrm{C}_{14} \mathrm{H}_{23}$ (Structure I) and $\mathrm{C}_{16} \mathrm{H}_{25}$ (Structure II) are indicative of triterpanes and steranes, respectively. Some molecular ions such as $\mathrm{C}_{29} \mathrm{H}_{50} \mathrm{O}_{2}$,

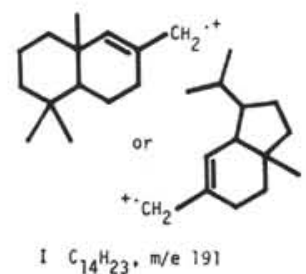<smiles>C=C1CCC2C(CCC3CCCCC32)C1</smiles>

II $\mathrm{C}_{16} \mathrm{H}_{25}, \mathrm{~m} / \mathrm{e} 217$

$\mathrm{C}_{28} \mathrm{H}_{44} \mathrm{O}$ and $\mathrm{C}_{30} \mathrm{H}_{50}$ were also detected. Again alkanes, carboxylic acids or esters and contaminants are not significant constituents in these data.

The data for the benzene/methanol extract from Sample 147B-7-4 (from 67 meters depth) are shown in Figure 11. It 
TABLE 2

Elemental Analyses for the Site 147 Samples

\begin{tabular}{|c|c|c|c|c|}
\hline & \multirow[b]{2}{*}{ Element } & \multicolumn{3}{|c|}{$\begin{array}{c}\text { Sample } \\
\text { (Entries in Per Cent) }\end{array}$} \\
\hline & & $6 \mathrm{~m}$ & $67 \mathrm{~m}$ & $138 \mathrm{~m}$ \\
\hline Total $\mathrm{C}^{\mathrm{a}}$ & & 6.4 & 4.8 & 5.7 \\
\hline Organic $\mathrm{C}^{\mathrm{a}}$ & & 3.4 & 1.6 & 2.7 \\
\hline Carbonate $\mathrm{Ca}^{\mathrm{a}}$ & & 14.9 & 26.8 & 24.4 \\
\hline \multirow[t]{5}{*}{$\begin{array}{l}\text { Total sample (as received } \\
\text { and dried) }\end{array}$} & C & 2.53 & 4.18 & 2.31 \\
\hline & $\mathrm{H}$ & 0.75 & 0.89 & 0.88 \\
\hline & $\mathrm{N}$ & 0.30 & 0.24 & 0.14 \\
\hline & S & 0.40 & 0.86 & 1.25 \\
\hline & Ash & 87.4 & 85.8 & 89.8 \\
\hline \multirow[t]{5}{*}{$\begin{array}{l}\text { Sample (dried, after water } \\
\text { wash) }\end{array}$} & $\mathrm{C}$ & 4.11 & 4.52 & 4.65 \\
\hline & $\mathrm{H}$ & 0.80 & 0.88 & 0.76 \\
\hline & $\mathrm{N}$ & 0.57 & 0.26 & 0.11 \\
\hline & S & 0.62 & 1.10 & 0.95 \\
\hline & Ash & 85.3 & 85.4 & 80.3 \\
\hline \multirow{5}{*}{$\begin{array}{l}1 \mathrm{~N} \mathrm{HCl} \text { treated sample } \\
\text { (dried, after water wash) }\end{array}$} & & 225 & 253 & 219 \\
\hline & $\mathrm{H}$ & 1.06 & 1.01 & 0.95 \\
\hline & $\mathrm{N}$ & 0.26 & 0.19 & 0.23 \\
\hline & S & 3.39 & 3.17 & 4.59 \\
\hline & Ash & 89.3 & 89.0 & 89.8 \\
\hline
\end{tabular}

${ }^{\mathrm{a} D a t a}$ supplied by DSDP staff.

appears to be a rather aromatic and functionalized mixture with significant amounts of alkanes and triterpenoidal compounds. The alkane series $\mathrm{C}_{n} \mathrm{H}_{2 n+2}$ is present for $n=17-23$ and 26-29. Olefinic hydrocarbons and steroidal compounds are present, but in lower concentrations than in the 6-meter heptane fraction. The presence of triterpenoidal compounds is indicated by the peak of composition $\mathrm{C}_{14} \mathrm{H}_{23}$ (Structure I) and molecular ions such as $\mathrm{C}_{29} \mathrm{H}_{50} \mathrm{O}_{2}, \mathrm{C}_{30} \mathrm{H}_{48} \mathrm{O}, \mathrm{C}_{30} \mathrm{H}_{52} \mathrm{O}$, and $\mathrm{C}_{28} \mathrm{H}_{46}$. Certain polynuclear aromatic hydrocarbons are present in significant amounts, for example, the peaks of composition $\mathrm{C}_{22} \mathrm{H}_{16}$, a dibenzdihydroanthracene or dimethylperylene, and $\mathrm{C}_{21} \mathrm{H}_{14}$, a dibenzofluorene. Contaminants are detectable in minor amounts only.

The data for the benzene and methanol extract from Sample $147 \mathrm{C}-2-1^{+}$(from 138 meters depth) are shown in Figure 12. Again, the bulk of this mixture consists of polar compounds with a somewhat aromatic character. The peak at $\mathrm{m} / \mathrm{e} 191$ (Structure I) is above background and the peak of composition $\mathrm{C}_{16} \mathrm{H}_{25}$ (Structure II) is also evident, indicating both terpenoidal and steroidal compounds are present in this mixture. The only molecular ion above background in these data is $\mathrm{C}_{29} \mathrm{H}_{50} \mathrm{O}_{2}$. Alkanes, alkenes and carboxylic acids or esters were not detected above the general background. Minor amounts of contaminants are present. Phthalate esters are indicated by the peak of composition $\mathrm{C}_{8} \mathrm{H}_{5} \mathrm{O}_{3}$ (Simoneit et al., 1972b). Dibutyl glutarate and dibutyl pimelate, probably from the core tube (Simoneit et al., 1972), are also found in the $\mathrm{C} / \mathrm{H} \mathrm{O}_{3}$ data.

The total benzene and methanol soluble fractions from the exhaustive extracts of the 6-meter and 67-meter samples were analyzed by GC/MS. Certain mass spectra

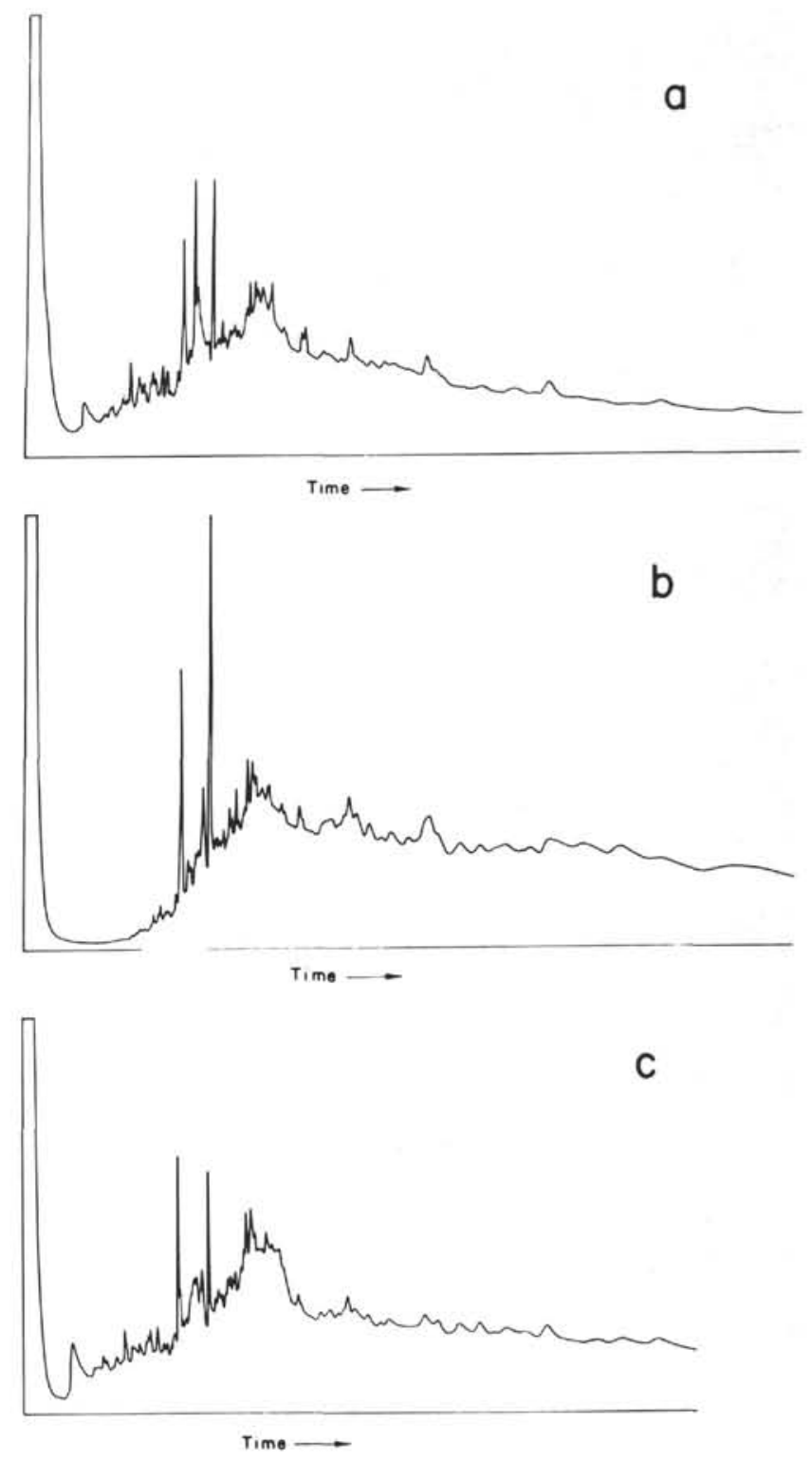

Figure 7. Gas liquid chromatograms of the following: (a) Heptane soluble fraction of the 6-meter sample $(2.8 \mu \mathrm{l}$ of $6.0 \mathrm{wt} \%$ solution in chloroform); (b) Heptane soluble fraction of the 67-meter sample $(3.0 \mu \mathrm{l}$ of $10 \mathrm{wt} \%$ solution in chloroform); (c) Heptane soluble fraction of the 138-meter sample $(2.9 \mu \mathrm{l}$ of $10 \mathrm{wt} \%$ solution in chloroform). GC conditions as cited in Figure 6.

from the various GC/MS analyses were identified by use of a compound classifier (Smith, 1972). The salient results for the 6-meter sample are shown in Figure 13 and the major constituents of the mixture are listed in Table 3. The total ionization sum plot (Figure 13a; compare also GC trace, Figure 2e) exhibits a bimodal distribution. The group of peaks at lower retention times consists mainly of olefins (the phytadienes) and the second group consists essentially of a mixture of sterols, steranes, and alkanes. The hydrocarbons are the major constituents and consist mainly of mono- and diolefins with some saturated homologs. The range is from $C_{13}$ to $C_{31}$. The phytadiene and norphytene 

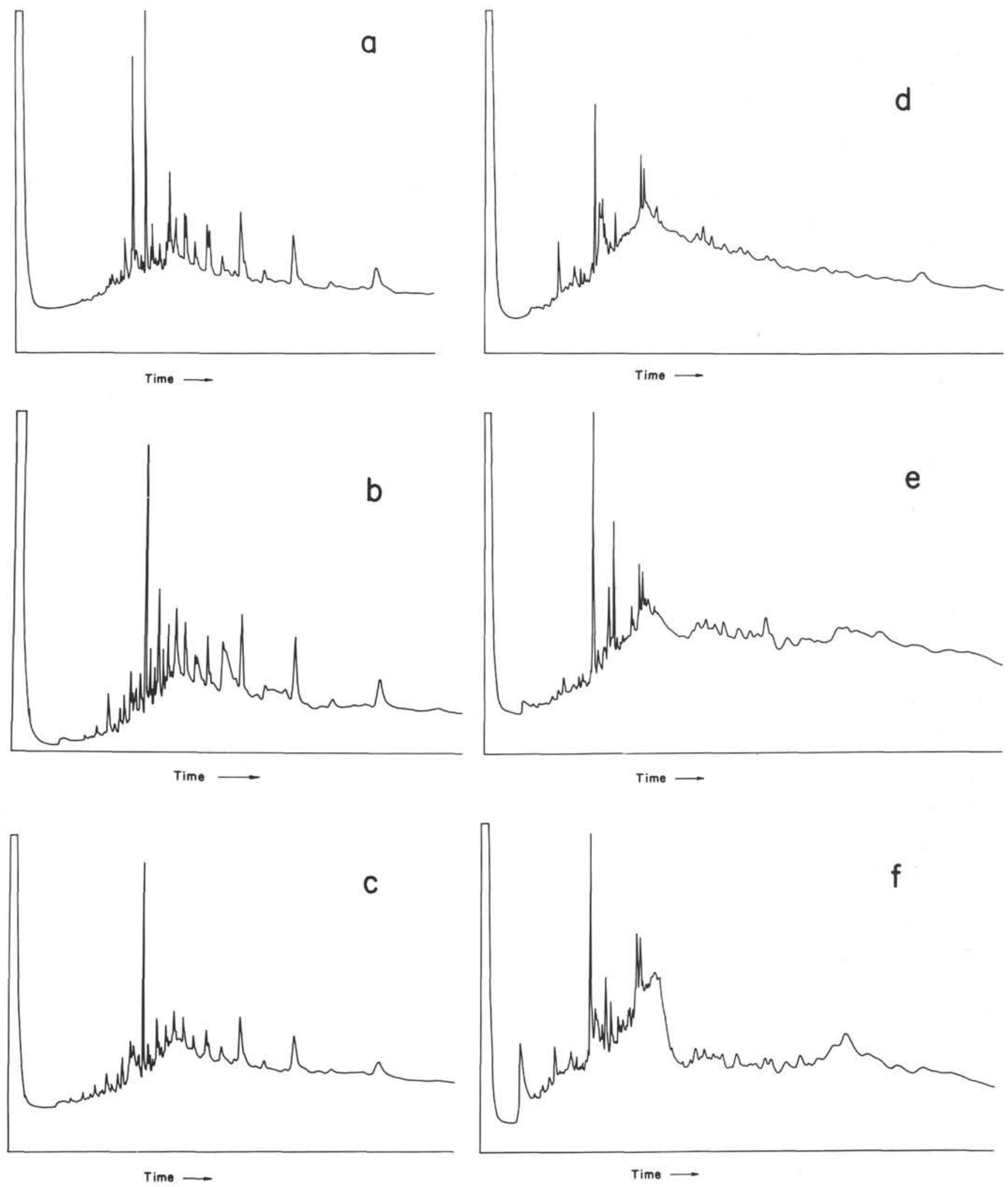

Figure 8. Gas liquid chromatograms of the following: (a) Normal fraction (urea adduct) of the 6-meter sample $(1.6 \mu 1$ of 11 wt \% solution in chloroform); (b) Normal fraction (urea adduct) of the 67-meter sample (2.7 $\mu 1$ of 4 wt \% solution in chloroform); (c) Normal fraction (urea adduct) of the 138-meter sample (1.3 $\mu 1$ of $10 \mathrm{wt} \%$ solution in chloroform); (d) Branched/cyclic fraction (non adducted) of the 6-meter sample (1.3 $\mu 1$ of $10 \mathrm{wt} \%$ in chloroform); (e) Branched cyclic fraction (non adducted) of the 67-meter sample (1.2 $\mu 1$ of 11 wt \% in chloroform); (f) Branched/cyclic fraction (non adducted) of the 138-meter sample (1.7 $\mu 1$ of $10 \mathrm{wt} \%$ in chloroform). GC conditions as cited in Figure 6. 
isomers (Blumer and Thomas, 1965a and b) are of special interest, since they are present in this sample in substantial amounts. The base peaks at $\mathrm{m} / \mathrm{e} 68$ and $\mathrm{m} / \mathrm{e} 82$ in the mass spectra of the phytadienes are due to rearrangement fragmentation and their ion sums are shown in Figure 13b. The scan 94 spectrum (Figure 13d) fits the fragmentation pattern of neophytadiene (Structure III). An example of

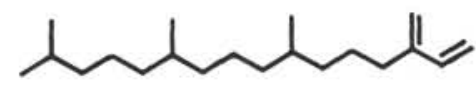

III $\mathrm{C}_{20} \mathrm{H}_{38}, \mathrm{~m} / \mathrm{e} 278$

the rearrangement fragmentation leading to the oddelectron ion at m/e 68 or 82 is shown in Structure IV. The major fragmentation of neophytadiene is indicated in Structure V. The scan 97 spectrum fits the fragmentation

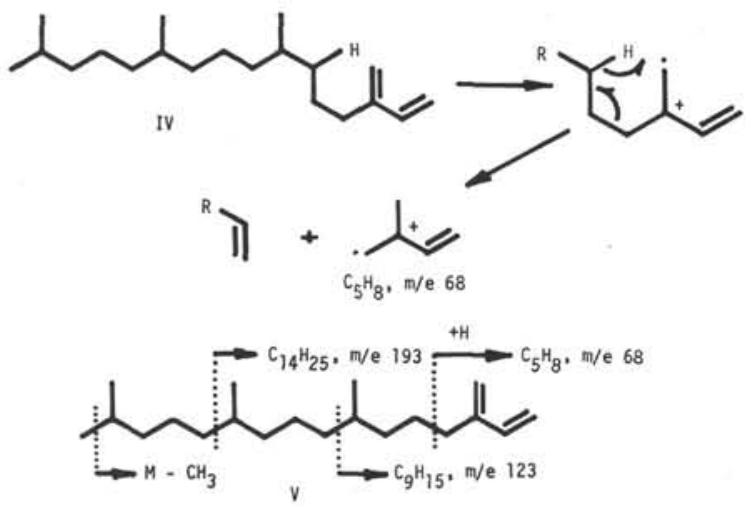

pattern of 1,3-phytadiene (Structure VI) and is identical to the scan 100 spectrum (Figure 13e). From the GC retention indices of Blumer and Thomas (1965a), the scan 97 spectrum represents the cis isomer and the scan 100 spectrum the trans isomer. The major fragmentation of 1,3-phytadiene (Figure 13e) is indicated in Structure VII.

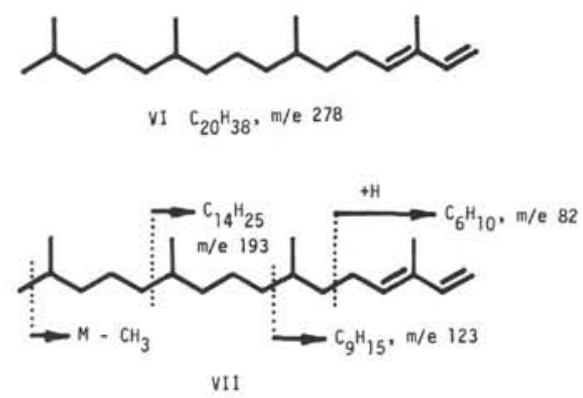

The scan 102 spectrum fits the fragmentation pattern of 2,4-phytadiene (Structure VIII) as indicated in Structure IX.

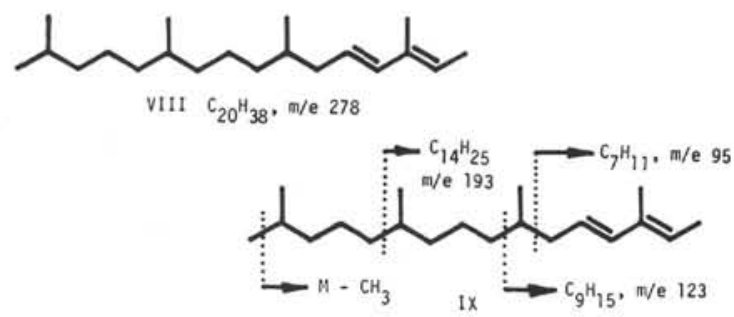

The norphytene isomers $\left(\mathrm{C}_{19} \mathrm{H}_{38}, \mathrm{~m} / \mathrm{e} 266\right)$ are unresolved and are found in the spectra at scans 79 through 81 . The three isomers described by Blumer and Thomas (1965b) appear to be present in these spectra. The major fragmentations for these isomers are indicated in Structures $\mathrm{X}$ to $\mathrm{XII}$ and all the major fragment ions are present

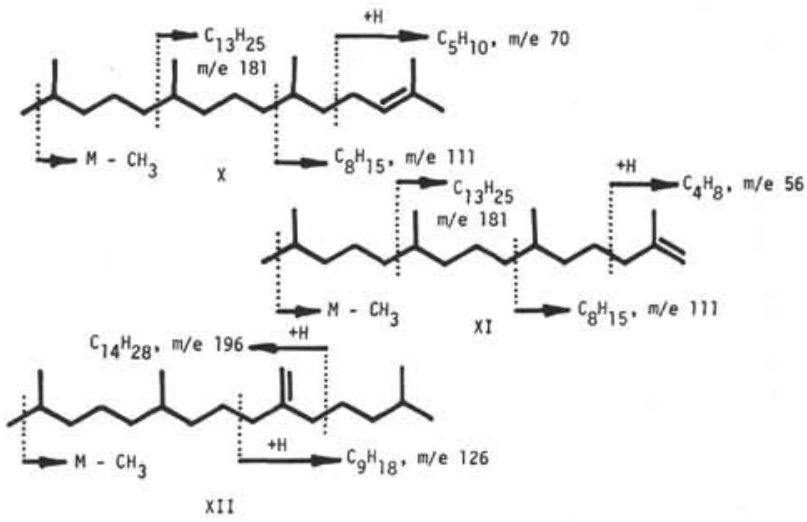

in the spectra. An assessment as to which isomer is the most abundant cannot be made from these data but use of capillary GC columns would undoubtedly achieve resolution allowing a comparison to be made of peak areas.

The mass spectra of the higher molecular weight compounds indicate mixtures, but some conclusions can be drawn. The major steroidal compounds are sterols, as deduced from their molecular ions $\left(\mathrm{M}^{+}\right)$and fragment peaks corresponding to loss of a methyl radical and the elements of water from the molecular ion. The scan 196 spectrum (Figure 13a) indicates minor other compounds and exhibits a peak m/e 368 of composition $\mathrm{C}_{27} \mathrm{H}_{44}$ with an $\mathrm{M}^{+}$-methyl radical, but no $\mathrm{M}^{+} \cdot \mathrm{H}_{2} \mathrm{O}$. A possible structure for this compound is cholestadiene (Structure XIII). One of the major components of the scan 204 spectrum (Figure 13a) fits the fragmentation pattern for cholesterol (Structure XIV). The major constituent of the scan 208

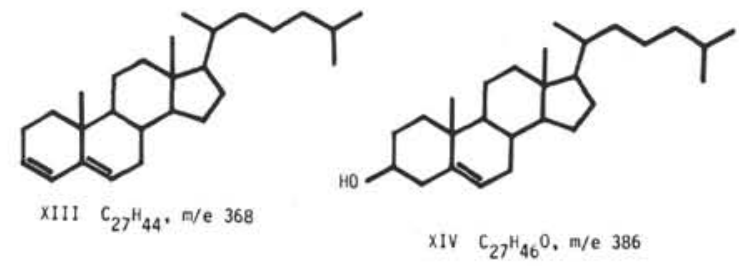

spectrum (Figure 13a) appears to fit the fragmentation pattern for a sterol of composition $\mathrm{C}_{28} \mathrm{H}_{44} \mathrm{O}$, possibly ergosterol (Structure XV). The most abundant sterol in this mixture is indicated in the scan 212 spectrum (Figure 13a), the fragmentation fitting a composition $\mathrm{C}_{2}{ }_{9} \mathrm{H}_{50} \mathrm{O}$, probably $\beta$-sitosterol (Structure XVI).

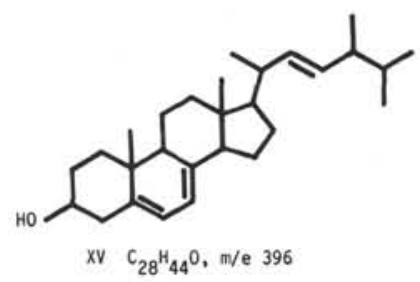



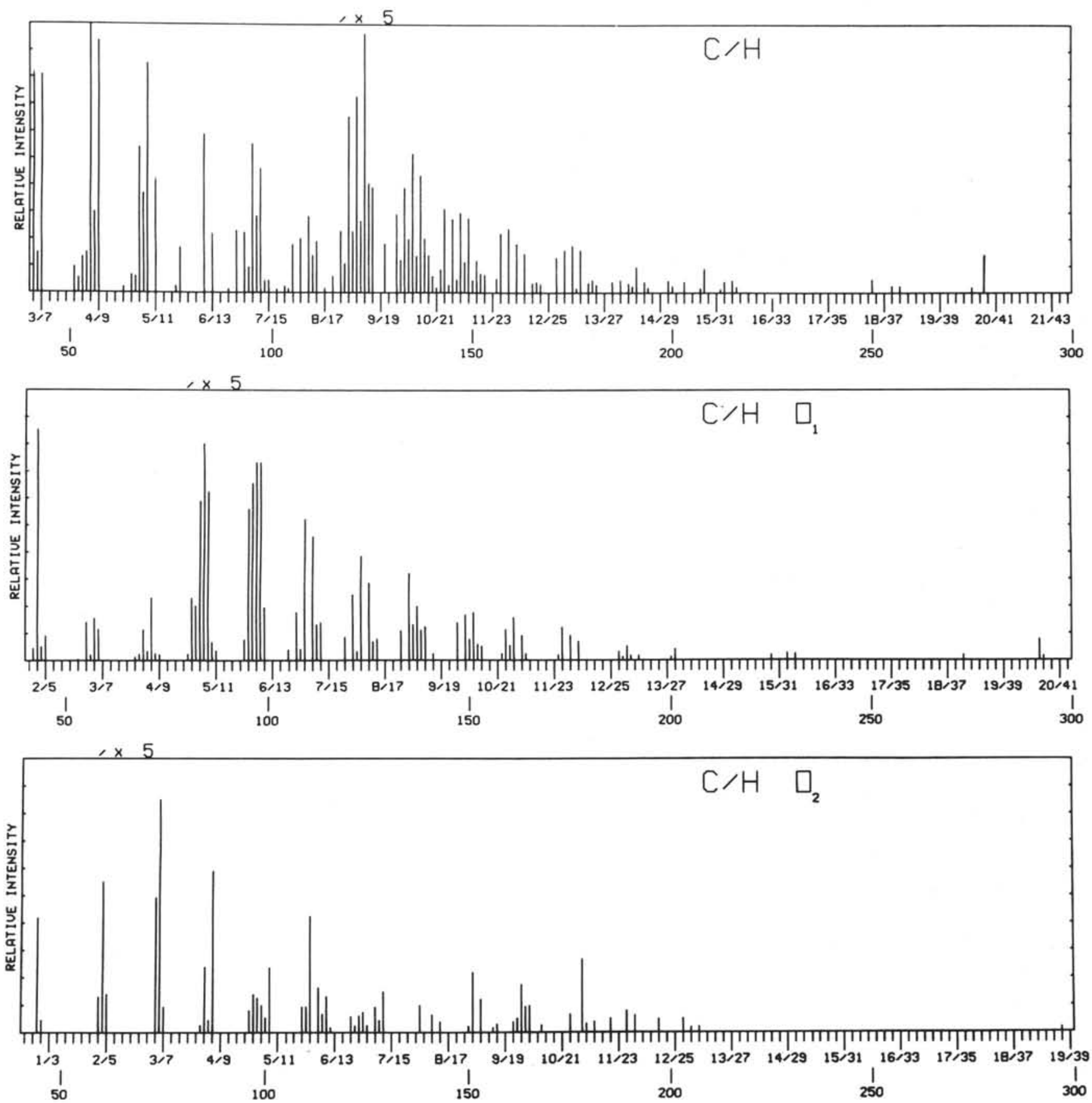

Figure 9. Partial high resolution mass spectrometric data for the total benzene and methanol extract from Sample 147B-1-4 (6 $\mathrm{m}$ below sea bed).

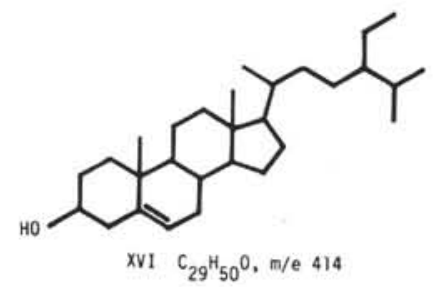

Minor amounts of carboxylic acid methyl esters are present in this mixture (Figure 13c, the McLafferty rearrangement peak $\mathrm{m} / \mathrm{e} 74$ ), with methyl palmitate as the most abundant of the series. Extraneous organic contaminants are negligible.

The total ionization sum plot of the GC/MS analysis of the benzene and methanol soluble fraction from the 67-meter sample is shown in Figure 14 (compare the GC trace in Figure 6c) and the major constituents of the mixture are listed in Table 4. The major components are monoölefinic and saturated hydrocarbons and steroidal compounds. The hydrocarbon series $\mathrm{C}_{n} \mathrm{H}_{2 n+2}$ ranges from $n=19$ to 32 and $\mathrm{C}_{n} \mathrm{H}_{2 n}$ ranges from $n=17$ to 32 , with an odd/even predominance and a bimodal distribution. The 

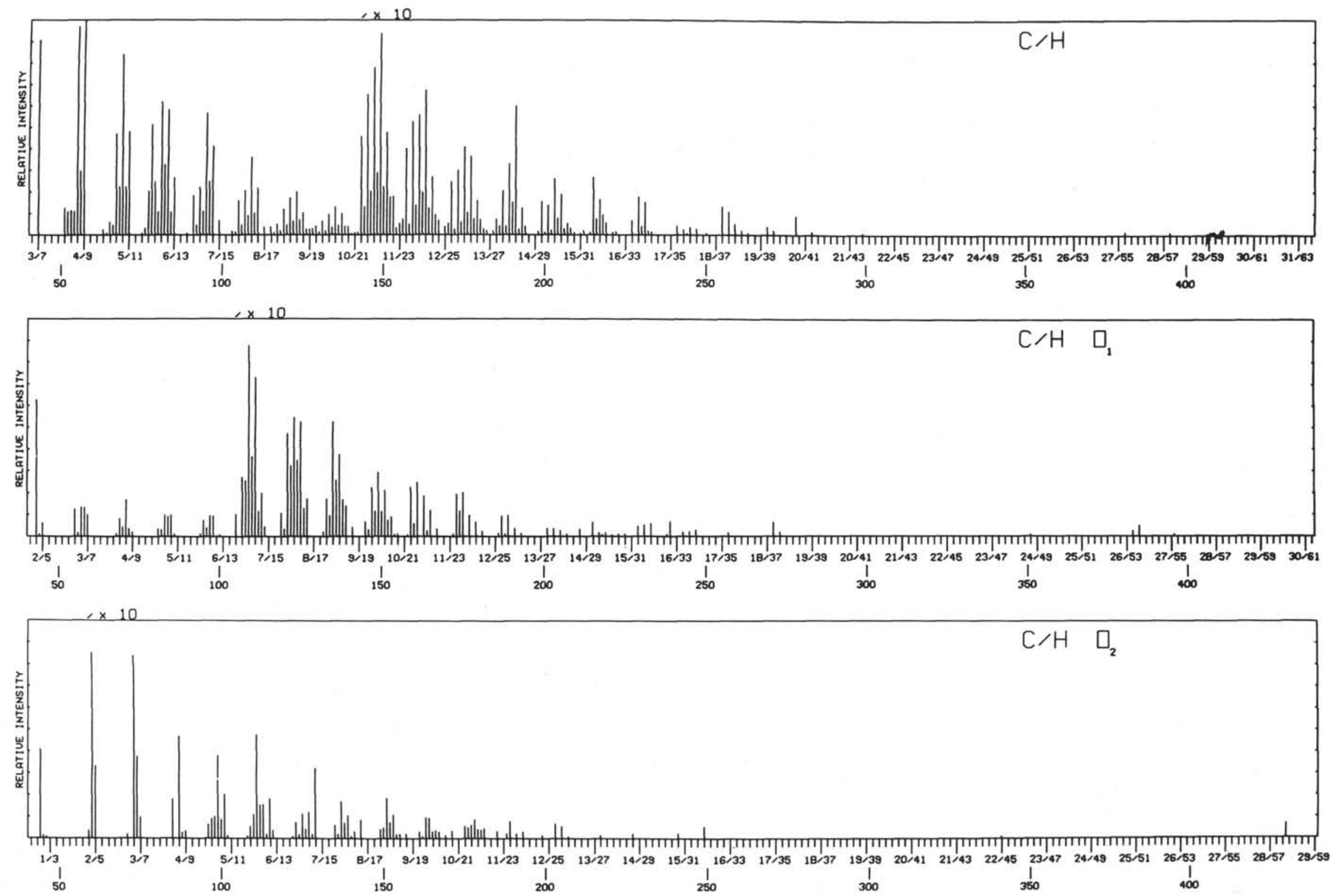


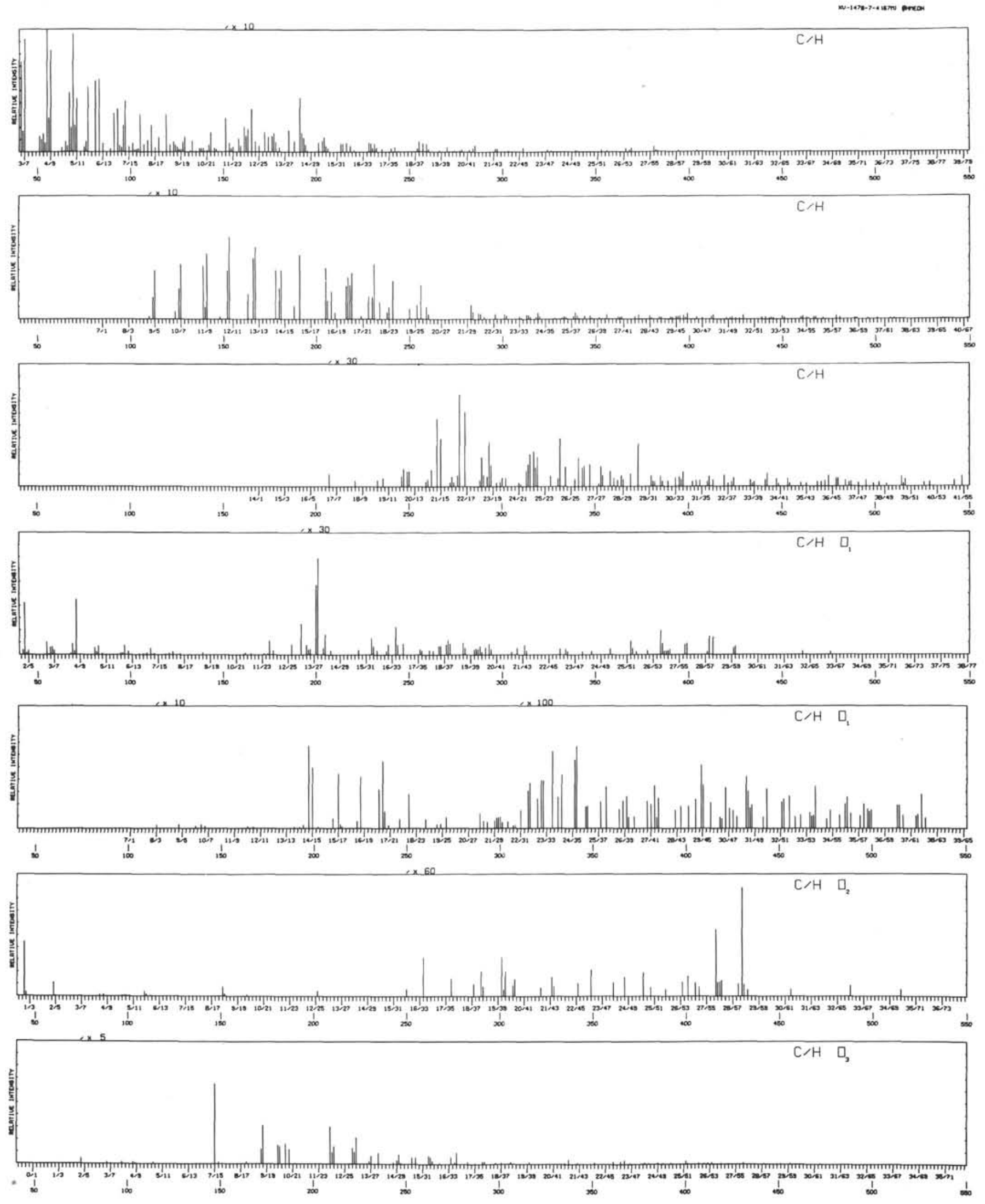

Figure 11. Partial high resolution mass spectrometric data for the total benzene and methanol extract from Sample 147B-7-4 (67 $\mathrm{m}$ below sea bed). 


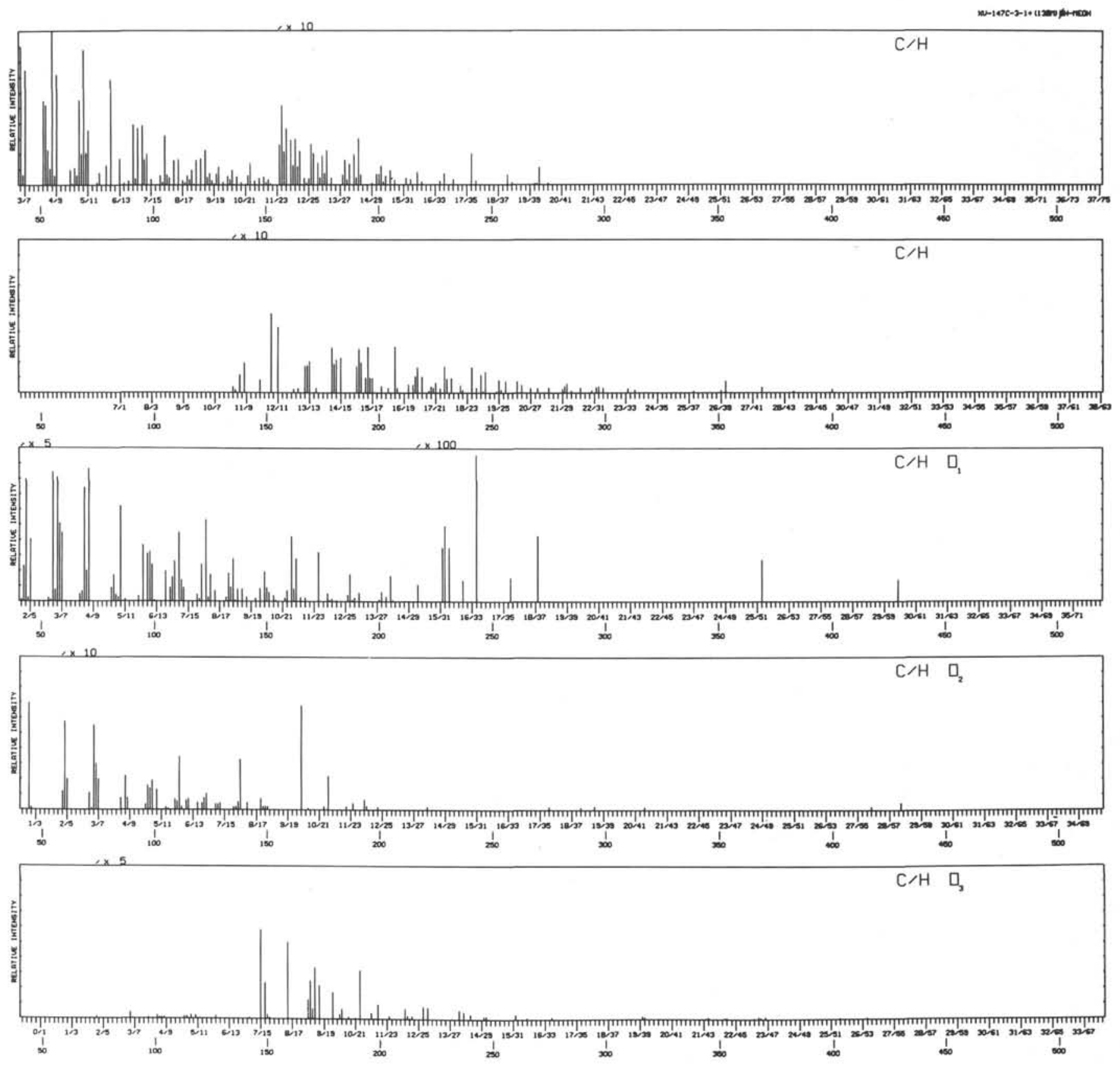

Figure 12. Partial high resolution mass spectrometric data for the total benzene and methanol extract from Sample 147C-3-1+(138 m below sea bed $)$.

phytadienes present in the 6-meter sample are very much less concentrated; only what is probably 1,3-phytadiene (Structure VI) is indicated by the scan 106 spectrum. The saturated isoprenoidal hydrocarbons pristane and phytane are present in significant amounts. No sterols or carboxylic acid methyl esters were detected above background. The steranes detected are of the following compositions (all spectra are mixtures): scan $229-\mathrm{C}_{27} \mathrm{H}_{46}$, possibly cholestene, and $\mathrm{C}_{27} \mathrm{H}_{48}$, possibly cholestane (Structure XVII); scan $242-\mathrm{C}_{29} \mathrm{H}_{50}$, possibly stigmastene, and $\mathrm{C}_{29} \mathrm{H}_{52}$, possibly stigmastane (Structure XVIII). Phthalate ester contamination, probably from bagging material, is minor in this mixture.

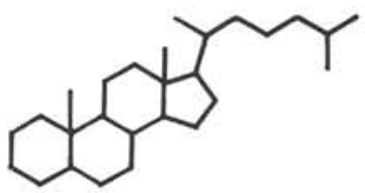

XVII $\mathrm{C}_{27} \mathrm{H}_{48}, \mathrm{~m} / \mathrm{e} 372$

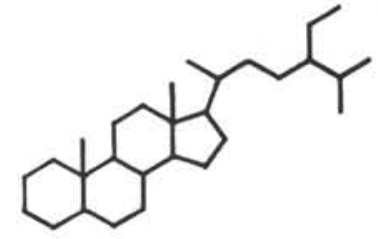

XVIII $\quad C_{29} \mathrm{H}_{52}, \mathrm{~m} / \mathrm{e} 400$
The heptane soluble fractions of the total extracts from the three core samples were separated into normal and branched/cyclic components by urea adduction. The three normal fractions were analyzed by GC/MS and GC. The 
B. R. SIMONEIT, W. G. HOWELLS, A. L. BURLINGAME
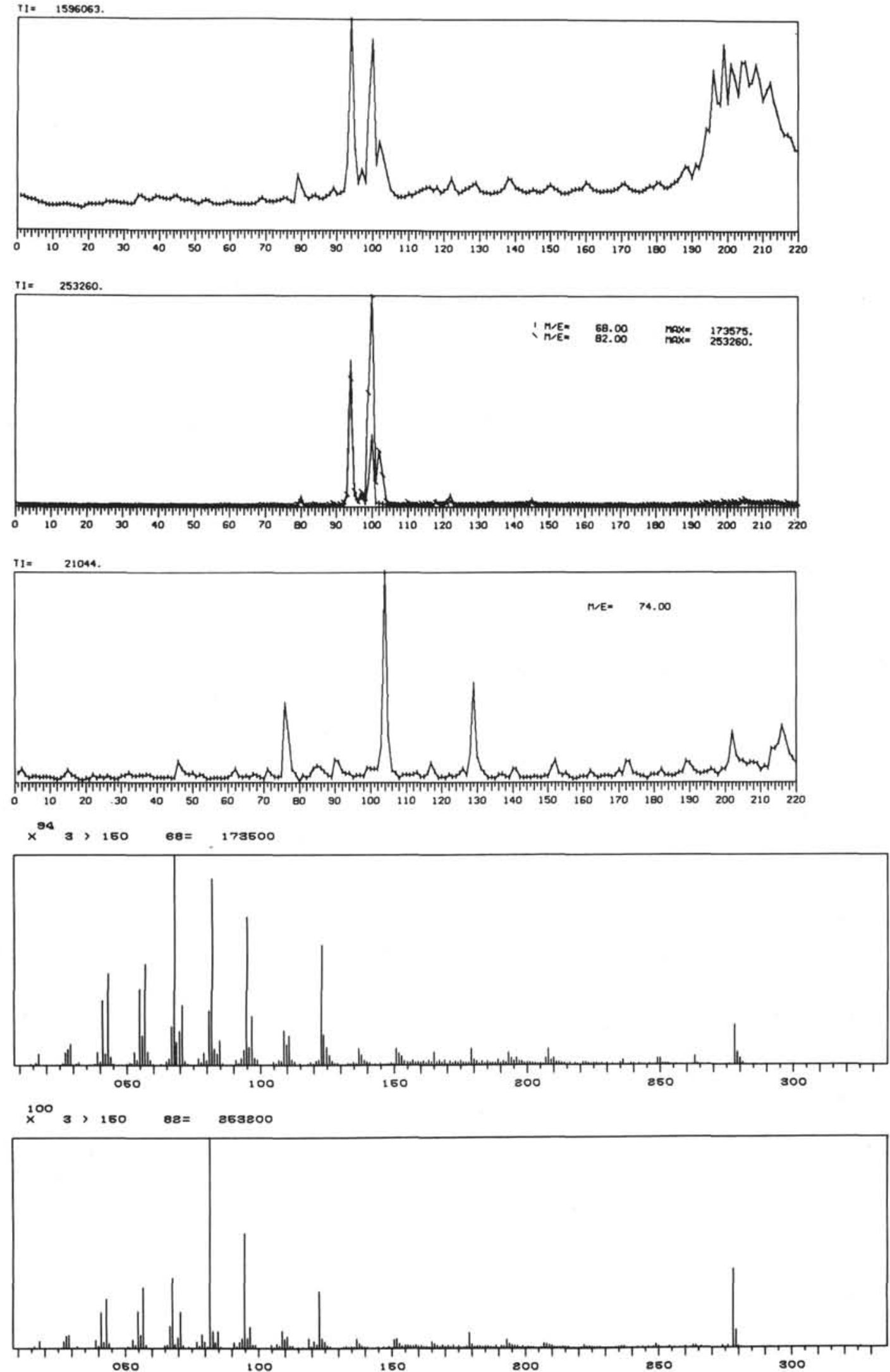

Figure 13. GC/MS data for the benzene and methanol soluble fraction from the exhaustive extract of Sample 147B-1-4 (6 m below sea bed). (GC conditions as cited in Figure 2). (a) total ionization sum plot; (b) m/e 68 and m/e 82 sum plot; (c) m/e 74 sum plot; (d) mass spectrum scan 94; (e) mass spectrum scan 100. 
PRELIMINARY ORGANIC GEOCHEMICAL ANALYSES, SITE 147

TABLE 3

Major Components of the Benzene/Methanol Soluble Fraction from the Total Extract of Sample 147B-1-4 (6 m Below Sea Bed) as Determined by GC/MS

\begin{tabular}{|c|c|c|c|}
\hline \multirow{2}{*}{$\begin{array}{l}\text { Spectrum } \\
\text { Scan No.a } \\
35\end{array}$} & \multirow{2}{*}{$\begin{array}{l}\text { Compound Name } \\
\text { tridecadiene }\end{array}$} & \multicolumn{2}{|c|}{$\begin{array}{l}\text { Composition and } \\
\text { Molecular Weight }\end{array}$} \\
\hline & & $\mathrm{C}_{13} \mathrm{H}_{24}$ & 180 \\
\hline 39 & unknown & $\mathrm{C}_{14} \mathrm{H}_{22}$ & 190 \\
\hline \multirow[t]{3}{*}{44} & tetradecadiene & $\mathrm{C}_{14} \mathrm{H}_{26}$ & 194 \\
\hline & unknown & $\mathrm{C}_{15} \mathrm{H}_{24}$ & 204 \\
\hline & unknown & $\mathrm{C}_{15} \mathrm{H}_{26}$ & 206 \\
\hline 46 & methyl laurate & $\mathrm{C}_{13} \mathrm{H}_{26} \mathrm{O}_{2}$ & 214 \\
\hline \multirow[t]{2}{*}{53} & pentadecane & $\mathrm{C}_{15} \mathrm{H}_{32}$ & 212 \\
\hline & pentadecene & $\mathrm{C}_{15} \mathrm{H}_{30}$ & 210 \\
\hline \multirow[t]{2}{*}{69} & hexadecene & $\mathrm{C}_{16} \mathrm{H}_{32}$ & 224 \\
\hline & hexadecadiene & $\mathrm{C}_{16}{ }^{\mathrm{H}_{30}}$ & 222 \\
\hline 75 & heptadecene & $\mathrm{C}_{17} \mathrm{H}_{34}$ & 238 \\
\hline 76 & methyl myristate & $\mathrm{C}_{15} \mathrm{H}_{30} \mathrm{O}_{2}$ & 242 \\
\hline 79 & norphy tene & $\mathrm{C}_{19} \mathrm{H}_{38}$ & 266 \\
\hline 89 & octadecane & $\mathrm{C}_{18} \mathrm{H}_{38}$ & 254 \\
\hline \multirow[t]{2}{*}{93} & phytadiene & $\mathrm{C}_{20} \mathrm{H}_{38}$ & 278 \\
\hline & phytene & $\mathrm{C}_{20} \mathrm{H}_{40}$ & 280 \\
\hline 94 & phytadiene & $\mathrm{C}_{20} \mathrm{H}_{38}$ & 278 \\
\hline \multirow[t]{2}{*}{97} & phytadiene & $\mathrm{C}_{20} \mathrm{H}_{38}$ & 278 \\
\hline & eicosene & $\mathrm{C}_{20} \mathrm{H}_{40}$ & 280 \\
\hline 100 & phytadiene & $\mathrm{C}_{20} \mathrm{H}_{38}$ & 278 \\
\hline \multirow[t]{2}{*}{101} & phytadiene & $\mathrm{C}_{20} \mathrm{H}_{38}$ & 278 \\
\hline & heneicosadiene & $\mathrm{C}_{21} \mathrm{H}_{40}$ & 292 \\
\hline 102 & phytadiene & $\mathrm{C}_{20} \mathrm{H}_{38}$ & 278 \\
\hline \multirow[t]{2}{*}{104} & methyl palmitate & $\mathrm{C}_{17} \mathrm{H}_{34} \mathrm{O}_{2}$ & 270 \\
\hline & phytadiene & $\mathrm{C}_{20} \mathrm{H}_{38}$ & 278 \\
\hline 117 & methyl margarate & $\mathrm{C}_{18} \mathrm{H}_{36} \mathrm{O}_{2}$ & 284 \\
\hline 122 & dibutyl azelate ${ }^{\mathrm{b}}$ & $\mathrm{C}_{17} \mathrm{H}_{32} \mathrm{O}_{4}$ & 300 \\
\hline \multirow[t]{2}{*}{129} & methyl stearate & $\mathrm{C}_{19} \mathrm{H}_{38} \mathrm{O}_{2}$ & 298 \\
\hline & heneicosane & $\mathrm{C}_{21} \mathrm{H}_{44}$ & 296 \\
\hline \multirow[t]{3}{*}{$138-139$} & docosene & $\mathrm{C}_{22} \mathrm{H}_{44}$ & 308 \\
\hline & N-docosane & $\mathrm{C}_{22} \mathrm{H}_{46}$ & 310 \\
\hline & tricosatetraene & $\mathrm{C}_{23} \mathrm{H}_{40}$ & 316 \\
\hline \multirow[t]{3}{*}{150} & tricosene & $\mathrm{C}_{23} \mathrm{H}_{46}$ & 322 \\
\hline & $n$-tricosane & $\mathrm{C}_{23} \mathrm{H}_{48}$ & 324 \\
\hline & tricosadiene & $\mathrm{C}_{23} \mathrm{H}_{44}$ & 320 \\
\hline 152 & methyl arachidate & $\mathrm{C}_{21} \mathrm{H}_{42} \mathrm{O}_{2}$ & 326 \\
\hline
\end{tabular}

TABLE 3 - Continued

\begin{tabular}{|c|c|c|c|}
\hline \multirow{2}{*}{$\begin{array}{c}\begin{array}{c}\text { Spectrum } \\
\text { Scan No.a }\end{array} \\
160\end{array}$} & \multirow{2}{*}{$\begin{array}{l}\text { Compound Name } \\
\text { tetracosene }\end{array}$} & \multicolumn{2}{|c|}{$\begin{array}{l}\text { Composition and } \\
\text { Molecular Weight }\end{array}$} \\
\hline & & $\mathrm{C}_{24} \mathrm{H}_{48}$ & 336 \\
\hline & $n$-tetracosane & $\mathrm{C}_{24} \mathrm{H}_{50}$ & 338 \\
\hline & tetracosadiene & $\mathrm{C}_{24} \mathrm{H}_{46}$ & 334 \\
\hline \multirow[t]{4}{*}{171} & $n$-pentacosane & $\mathrm{C}_{25} \mathrm{H}_{52}$ & 352 \\
\hline & pentacosene & $\mathrm{C}_{25} \mathrm{H}_{50}$ & 350 \\
\hline & pentocosadiene & $\mathrm{C}_{25} \mathrm{H}_{48}$ & 348 \\
\hline & pentacosatriene & $\mathrm{C}_{25} \mathrm{H}_{46}$ & 346 \\
\hline 172 & methyl behenate & $\mathrm{C}_{23} \mathrm{H}_{46} \mathrm{O}_{2}$ & 354 \\
\hline \multirow[t]{2}{*}{180} & $n$-hexacosane & $\mathrm{C}_{26} \mathrm{H}_{54}$ & 366 \\
\hline & hexacosene & $\mathrm{C}_{26} \mathrm{H}_{52}$ & 364 \\
\hline \multirow[t]{2}{*}{188} & $n$-heptacosane & $\mathrm{C}_{27} \mathrm{H}_{56}$ & 380 \\
\hline & heptacosene & $\mathrm{C}_{27} \mathrm{H}_{54}$ & 378 \\
\hline 190 & methyl lignocerate & $\mathrm{C}_{25} \mathrm{H}_{50} \mathrm{O}_{2}$ & 382 \\
\hline \multirow[t]{4}{*}{196} & octacosene & $\mathrm{C}_{28} \mathrm{H}_{56}$ & 392 \\
\hline & octacosadiene & $\mathrm{C}_{28} \mathrm{H}_{54}$ & 390 \\
\hline & octacosane & $\mathrm{C}_{28} \mathrm{H}_{58}$ & 394 \\
\hline & sterane & $\mathrm{C}_{27} \mathrm{H}_{44}$ & 368 \\
\hline \multirow[t]{3}{*}{199} & nonacosene & $\mathrm{C}_{29} \mathrm{H}_{58}$ & 406 \\
\hline & nonacosane & $\mathrm{C}_{29} \mathrm{H}_{60}$ & 408 \\
\hline & sterane & $\mathrm{C}_{27} \mathrm{H}_{46}$ & 370 \\
\hline \multirow[t]{4}{*}{201} & sterol & $\mathrm{C}_{27} \mathrm{H}_{44} \mathrm{O}$ & 384 \\
\hline & sterane & $\mathrm{C}_{28} \mathrm{H}_{50}$ & 386 \\
\hline & methyl cerotate & $\mathrm{C}_{27} \mathrm{H}_{54} \mathrm{O}_{2}$ & 410 \\
\hline & methyl hexacosenoate & $\mathrm{C}_{27} \mathrm{H}_{52} \mathrm{O}_{2}$ & 408 \\
\hline \multirow[t]{4}{*}{204} & triacontadiene & $\mathrm{C}_{30} \mathrm{H}_{58}$ & 418 \\
\hline & sterol & $\mathrm{C}_{27} \mathrm{H}_{46} \mathrm{O}$ & 386 \\
\hline & sterane & $\mathrm{C}_{29} \mathrm{H}_{48}$ & 396 \\
\hline & sterane & $\mathrm{C}_{29} \mathrm{H}_{50}$ & 398 \\
\hline \multirow[t]{4}{*}{208} & sterol & $\mathrm{C}_{30} \mathrm{H}_{52} \mathrm{O}$ & 428 \\
\hline & sterol & $\mathrm{C}_{28} \mathrm{H}_{44} \mathrm{O}$ & 396 \\
\hline & sterane & $\mathrm{C}_{30} \mathrm{H}_{54}$ & 414 \\
\hline & sterane & $\mathrm{C}_{30} \mathrm{H}_{52}$ & 412 \\
\hline \multirow[t]{4}{*}{212} & sterol & $\mathrm{C}_{29} \mathrm{H}_{50} \mathrm{O}$ & 414 \\
\hline & sterol & $\mathrm{C}_{30} \mathrm{H}_{52} \mathrm{O}$ & 428 \\
\hline & tetracontene & $\mathrm{C}_{31} \mathrm{H}_{62}$ & 434 \\
\hline & sterane & $\mathrm{C}_{32} \mathrm{H}_{56}$ & 440 \\
\hline \multirow[t]{3}{*}{218} & sterol & $\mathrm{C}_{29} \mathrm{H}_{50} \mathrm{O}$ & 414 \\
\hline & sterol & $\mathrm{C}_{30} \mathrm{H}_{52} \mathrm{O}$ & 428 \\
\hline & sterol & $\mathrm{C}_{31} \mathrm{H}_{50} \mathrm{O}$ & 438 \\
\hline
\end{tabular}

${ }^{\mathrm{a}}$ See Figure 13a.

bProbably core tube contamination. 


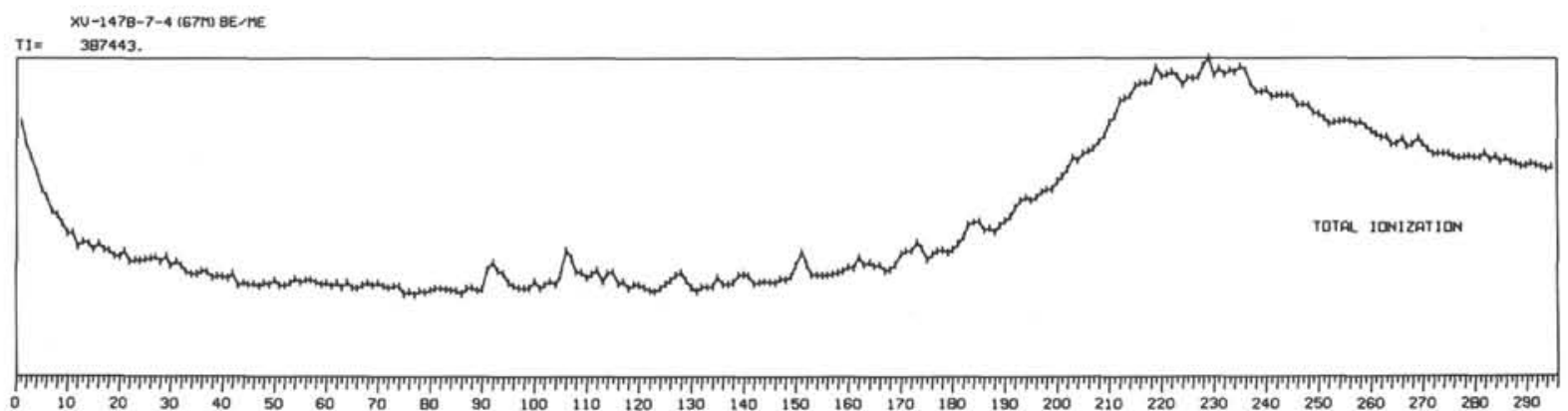

Figure 14. Total ionization sum plot for the GC/MS analysis of the benzene and methanol soluble fraction from the exhaustive extract of Sample $X V-147 B-7-4$ (67 $\mathrm{m}$ below sea bed). GC conditions as cited in Figure 2.

salient results for the 6-meter sample are shown in Figure 15 (GC trace in Figure 8a) and the major constituents are listed in Table 5. The major component is methyl palmitate (scan 81) and, as can be discerned from the $\mathrm{m} / \mathrm{e}$ 74 sum plot, the series $\mathrm{C}_{n} \mathrm{H}_{2 n} \mathrm{O}_{2}$ ranges from $n=14$ to 27 with an even/odd predominance. The saturated hydrocarbons are the major homologous series, $\mathrm{C}_{n} \mathrm{H}_{2 n+2}$, ranging from $n=18$ to 33 with a strong odd/even predominance above $n=23$. The series $\mathrm{C}_{n} \mathrm{H}_{2 n}$ is present only in minor amounts. Minor amounts of isoprenoidal compounds are also found, probably due to incomplete separation during the adduction procedure. Contamination from core tube plasticizers is significant. Dibutyl azelate (Simoneit et al., 1972 ) is one of the dominant peaks of the GC trace (scans 104-105 in Figure 15a). The presence of a suite of phthalate esters is indicated by the $\mathrm{m} / \mathrm{e} 149$ sum plot (Figure 15d), dioctyl phthalate being the most abundant homolog.

The most significant results for the normal fraction of the 67-meter sample are shown in Figure 16 (GC trace in Figure $8 \mathrm{~b}$ ) and the major components are listed in Table 6. The major peak (Figure 16a, scans 103-104) is dibutyl azelate probably derived from core tube contamination (Simoneit et al., 1972). Two higher homologs from the same source are also present in minor amounts. Phthalate ester contamination is indicated by the m/e 149 sum plot (Figure 16d); dioctyl phthalate is the most abundant component. Normal carboxylic acid methyl esters (m/e 74 sum plot - Figure 16c) of the series $\mathrm{C}_{n} \mathrm{H}_{2 n} \mathrm{O}_{2}$ are found in minor amounts and range from $n=12$ to $n=26$, with an even/odd predominance and maxima at $n=16$ and $n=24$. The major homologous series consist of saturated hydrocarbons, $\mathrm{C}_{n} \mathrm{H}_{2 n+2}$ for $n=21$ to 33 , with an odd/even predominance. The olefins, $\mathrm{C}_{n} \mathrm{H}_{2 n}$, are found in minor amounts for $n=20$ to 32 although not every homolog was detected.

The salient features of the GC/MS analysis of the normal fraction from the 138-meter sample are shown in Figure 17 (GC trace in Figure 8c) and the major components are listed in Table 7. Dibutyl azelate is again the major peak (Figure 17a - scan 102), but none of the other core tube contaminants was detected (Simoneit et al., 1972). The major series present are saturated hydrocarbons, $\mathrm{C}_{n} \mathrm{H}_{2 n+2}$, which range from $n=15$ to 33 , with an odd/even predominance and maximum at $n=29$. Olefinic and isopreoidal hydrocarbons were not detected. Normal carboxylic acid methyl esters (m/e 74 sum plot - Figure 17c) are present in significant amounts, and the series $\mathrm{C}_{n} \mathrm{H}_{2 n} \mathrm{O}_{2}$, ranges from $n=10$ to 26 , with an even/odd predominance and maxima at $n=16$ and 24 . Phthalate ester contaminants (m/e 149 sum plot - Figure 17d) are also quite significant, with dioctyl phthalate as the most abundant homolog.

The three branched/cyclic fractions from the adduction of the heptane soluble products were also subjected to $\mathrm{GC} / \mathrm{MS}$ analysis and the results are summarized in Table 8. The respective GC traces are found in Figure $8 \mathrm{~d}-\mathrm{f}$. The major component in all three samples is phytane accompanied by significant amounts of pristane, norphytene, phytene, and phytadiene. The presence of organic contaminants in these mixtures, mainly dibutyl azelate, is also evident. Olefinic hydrocarbons, mostly the acyclic series $\mathrm{C}_{n} \mathrm{H}_{2 n}$, are present for $n=11$ to 30 and a few alkanes were also detected. Minor amounts of carboxylic acid methyl esters are found. At shorter retention times a complex mixture of steroidal and triterpenoidal compounds is evident. The possible steroidal structures found are mainly cholestane (Structure XVII), stigmastane (Structure XVIII), cholesterol (Structure XIV), and $\beta$-sitosterol (Structure XVI). In the 67-meter and 138-meter samples, minor amounts of pentacyclic triterpanes were detected. The compositions found, $\mathrm{C}_{30} \mathrm{H}_{50}$ at $\mathrm{m} / \mathrm{e} 410$ and $\mathrm{C}_{30} \mathrm{H}_{52}$ at $\mathrm{m} / \mathrm{e} 412$, could possibly possess structures such as hopene (Structure XIX) or oleanane (Structure XX). The next
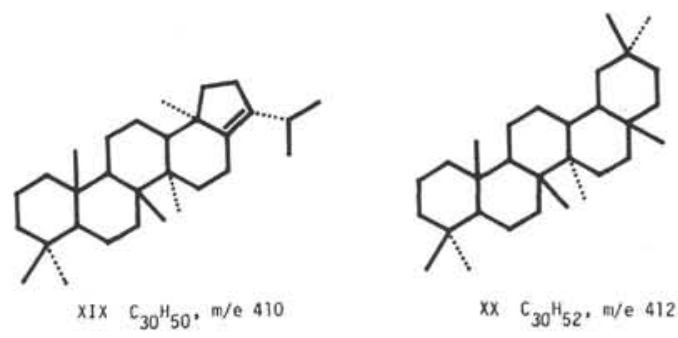

higher homolog of $\mathrm{C}_{30} \mathrm{H}_{52}$, namely $\mathrm{C}_{31} \mathrm{H}_{54}$, is evident at $\mathrm{m} / \mathrm{e} 426$. In the mass spectra all of these species exhibit fragments arising by loss of a methyl radical from the molecular ion as well as a characteristic base peak at m/e 191 (Structure I).

\section{DISCUSSION AND CONCLUSIONS}

The three Site 147 samples which were analyzed are all of Pleistocene age, sedimented under essentially uniform 
TABLE 4

Major Components of the Benzene/Methanol Soluble Fraction from the Total Extract of Sample 147B-7-4 (67 m Below Sea Bed) as Determined by GC/MS

\begin{tabular}{|c|c|c|c|}
\hline \multirow{2}{*}{$\begin{array}{l}\text { Spectrum } \\
\text { Scan No. }^{\mathrm{a}}\end{array}$} & \multirow{2}{*}{$\begin{array}{l}\text { Compound Name } \\
\text { diethyl phthalateb }\end{array}$} & \multicolumn{2}{|c|}{$\begin{array}{l}\text { Composition and } \\
\text { Molecular Weight }\end{array}$} \\
\hline & & $\mathrm{C}_{12} \mathrm{H}_{14} \mathrm{O}_{4}$ & 222 \\
\hline \multirow[t]{2}{*}{92} & pristane & $\mathrm{C}_{19} \mathrm{H}_{40}$ & 268 \\
\hline & heptadecene & $\mathrm{C}_{17} \mathrm{H}_{34}$ & 238 \\
\hline \multirow[t]{2}{*}{106} & phytadiene & $\mathrm{C}_{20} \mathrm{H}_{38}$ & 278 \\
\hline & phytane & $\mathrm{C}_{20} \mathrm{H}_{42}$ & 282 \\
\hline 112 & unknown & - & 246 \\
\hline \multirow[t]{2}{*}{114} & nonadecane & $\mathrm{C}_{19} \mathrm{H}_{40}$ & 268 \\
\hline & nonadecene & $\mathrm{C}_{19} \mathrm{H}_{38}$ & 266 \\
\hline 120 & dibutyl phthalate ${ }^{b}$ & $\mathrm{C}_{16} \mathrm{H}_{22} \mathrm{O}_{4}$ & 278 \\
\hline \multirow[t]{2}{*}{129} & eicosane & $\mathrm{C}_{20} \mathrm{H}_{42}$ & 282 \\
\hline & heneicosene & $\mathrm{C}_{21} \mathrm{H}_{42}$ & 294 \\
\hline 139 & heneicosane & $\mathrm{C}_{21} \mathrm{H}_{44}$ & 296 \\
\hline 151 & docosane & $\mathrm{C}_{22} \mathrm{H}_{46}$ & 310 \\
\hline \multirow[t]{2}{*}{162} & tricosane & $\mathrm{C}_{23} \mathrm{H}_{48}$ & 324 \\
\hline & tricosene & $\mathrm{C}_{23} \mathrm{H}_{46}$ & 322 \\
\hline 173 & tetracosane & $\mathrm{C}_{24} \mathrm{H}_{50}$ & 338 \\
\hline \multirow[t]{2}{*}{183} & pentacosane & $\mathrm{C}_{25} \mathrm{H}_{52}$ & 352 \\
\hline & pentacosene & $\mathrm{C}_{25} \mathrm{H}_{50}$ & 350 \\
\hline 193 & hexacosane & $\mathrm{C}_{26} \mathrm{H}_{54}$ & 366 \\
\hline 201 & heptacosadiene & $\mathrm{C}_{27} \mathrm{H}_{52}$ & 376 \\
\hline \multirow[t]{2}{*}{203} & heptacosane & $\mathrm{C}_{27} \mathrm{H}_{56}$ & 380 \\
\hline & heptacosene & $\mathrm{C}_{27} \mathrm{H}_{54}$ & 378 \\
\hline 213 & octacosane & $\mathrm{C}_{28} \mathrm{H}_{58}$ & 394 \\
\hline 220 & nonacosadiene & $\mathrm{C}_{29} \mathrm{H}_{56}$ & 404 \\
\hline \multirow[t]{2}{*}{222} & nonacosane & $\mathrm{C}_{29} \mathrm{H}_{60}$ & 408 \\
\hline & nonacosene & $\mathrm{C}_{29} \mathrm{H}_{58}$ & 406 \\
\hline \multirow[t]{3}{*}{229} & sterane & $\mathrm{C}_{27} \mathrm{H}_{46}$ & 370 \\
\hline & sterane & $\mathrm{C}_{27} \mathrm{H}_{48}$ & 372 \\
\hline & triacontadiene & $\mathrm{C}_{30} \mathrm{H}_{58}$ & 418 \\
\hline \multirow[t]{2}{*}{234} & triacontane & $\mathrm{C}_{30} \mathrm{H}_{62}$ & 422 \\
\hline & triacontene & $\mathrm{C}_{30} \mathrm{H}_{60}$ & 420 \\
\hline \multirow[t]{3}{*}{242} & sterane & $\mathrm{C}_{29} \mathrm{H}_{50}$ & 398 \\
\hline & sterane & $\mathrm{C}_{29} \mathrm{H}_{52}$ & 400 \\
\hline & hentriacontadiene & $\mathrm{C}_{31} \mathrm{H}_{60}$ & 432 \\
\hline \multirow[t]{2}{*}{244} & hentriacontene & $\mathrm{C}_{31} \mathrm{H}_{62}$ & 434 \\
\hline & hentriacontane & $\mathrm{C}_{31} \mathrm{H}_{64}$ & 436 \\
\hline \multirow[t]{2}{*}{255} & dotriacontene & $\mathrm{C}_{33} \mathrm{H}_{64}$ & 448 \\
\hline & dotriacontane & $\mathrm{C}_{32} \mathrm{H}_{66}$ & 450 \\
\hline
\end{tabular}

${ }^{\text {as See Figure } 14}$

${ }^{b}$ Probably bagging contamination. tropical conditions (Edgar et al., 1971). The bottom waters in the Cariaco Trench are and have been anoxic for a considerable length of time (Richards and Vaccaro, 1956; Edgar et al., 1971). It may be noted that the most recently deposited sediment, a shallow depth below the sea bed, contains 48 per cent water and water soluble materials, while the sediments at 67 meters and 138 meters both contain 36 per cent. The proportion of solvent extractable material is approximately the same for the 6-meter and 67-meter samples, but is somewhat higher for the 138 -meter sample. The value of 0.11 per cent (Table 1 ) for the organic extractable content of the 138-meter material includes, however, a substantial amount of plasticizer derived from the core tube. The nitrogen content (Table 2) decreases with depth of burial for the total and water washed samples. This trend may be correlated with the free amino acid content which decreases with sediment age (Wehmiller and Hare, 1972). Abelson and Hare (1970) postulate that amino acids are polymerized into kerogenlike material which then cannot be recovered by water extraction or acid hydrolysis.

The concentration histograms of the $n$-alkane and normal acids for these samples are shown in Figure 18.

The mineralogy throughout this core consists of dark olive green calcareous clay (Edgar et al., 1971). The carboxylic acid methyl esters found in these samples are formed during the extraction by the methanol in the solvent mixture, a conversion that is probably catalyzed by the acidic components of the clay. Arpino and Ourisson (1971) have observed that similar esterification processes occur during extraction of terrestrial clay-rich samples. The major acid ester found is methyl palmitate $\left(\mathrm{C}_{17} \mathrm{H}_{34} \mathrm{O}_{2}\right)$ with lower amounts of methyl myristate $\left(\mathrm{C}_{15} \mathrm{H}_{30} \mathrm{O}_{2}\right)$ and methyl stearate $\left(\mathrm{C}_{19} \mathrm{H}_{38} \mathrm{O}_{2}\right)$. The homologs above $\mathrm{C}_{20}$ are virtually absent, which indicates only a minor influx of terrigenous detritus. It has been shown that the fatty acid content for most species of blue green algae consists mainly of $\mathrm{C}_{14: 0}, \mathrm{C}_{14: 1}, \mathrm{C}_{16: 0}, \mathrm{C}_{16: 1}, \mathrm{C}_{18: 0}$ and $\mathrm{C}_{18: 1-3}$ (Han, 1970); marine aerobic bacteria contain mainly $C_{16: 0}$, $\mathrm{C}_{16: 1}, \mathrm{C}_{18: 0}$ and $\mathrm{C}_{18: 1}$ acids (Han, 1970). In all of these species, which are the mainstay in the foodchain of phytoplankton, the major portion of the fatty acid content is unsaturated. Since essentially no $C_{16: 1}$ acid was detected in the 6-meter sample it can be concluded that the unsaturated fatty acids are reduced or incorporated in the kerogen matrix over a geologic time period of less than $10^{3} \mathrm{y}$. Analysis of the acids liberated by $\mathrm{HC} 1$ treatment of the samples might permit substantiation of this conclusion, since carboxylic acids are also strongly adsorbed onto clay turbidites (Meyers and Quinn, 1971). Analysis of products arising from selective degradation of the kerogen (nonsolvent soluble, polymeric, organic matter) following acid demineralization could indicate the way in which the unsaturated fatty acids are bound in the polymeric matrix (Burlingame and Simoneit, 1968 and 1969).

The phytadiene and norphytene isomers (Blumer and Thomas, 1965a and b) were found in significant amounts in the 6-meter sample, but their concentrations were very much less in the 67-meter sample, and 138-meter samples. These phytadienes were also found in a sample of sediment that had been deposited under anoxic conditions approximately 6,000 y B.P. and which was located $40 \mathrm{~cm}$ 
6-UR

$T 1=3240402$

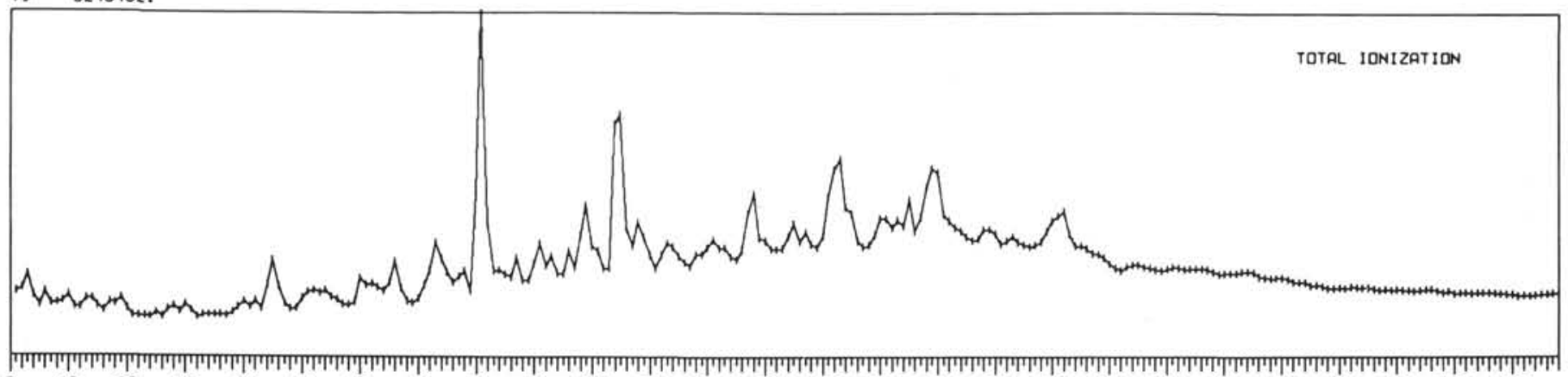

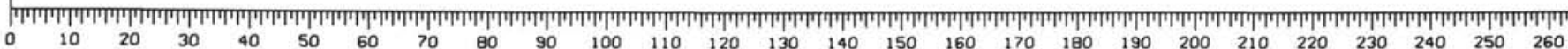
$I I=\quad \begin{array}{r}6-U A \\ 167446 .\end{array}$
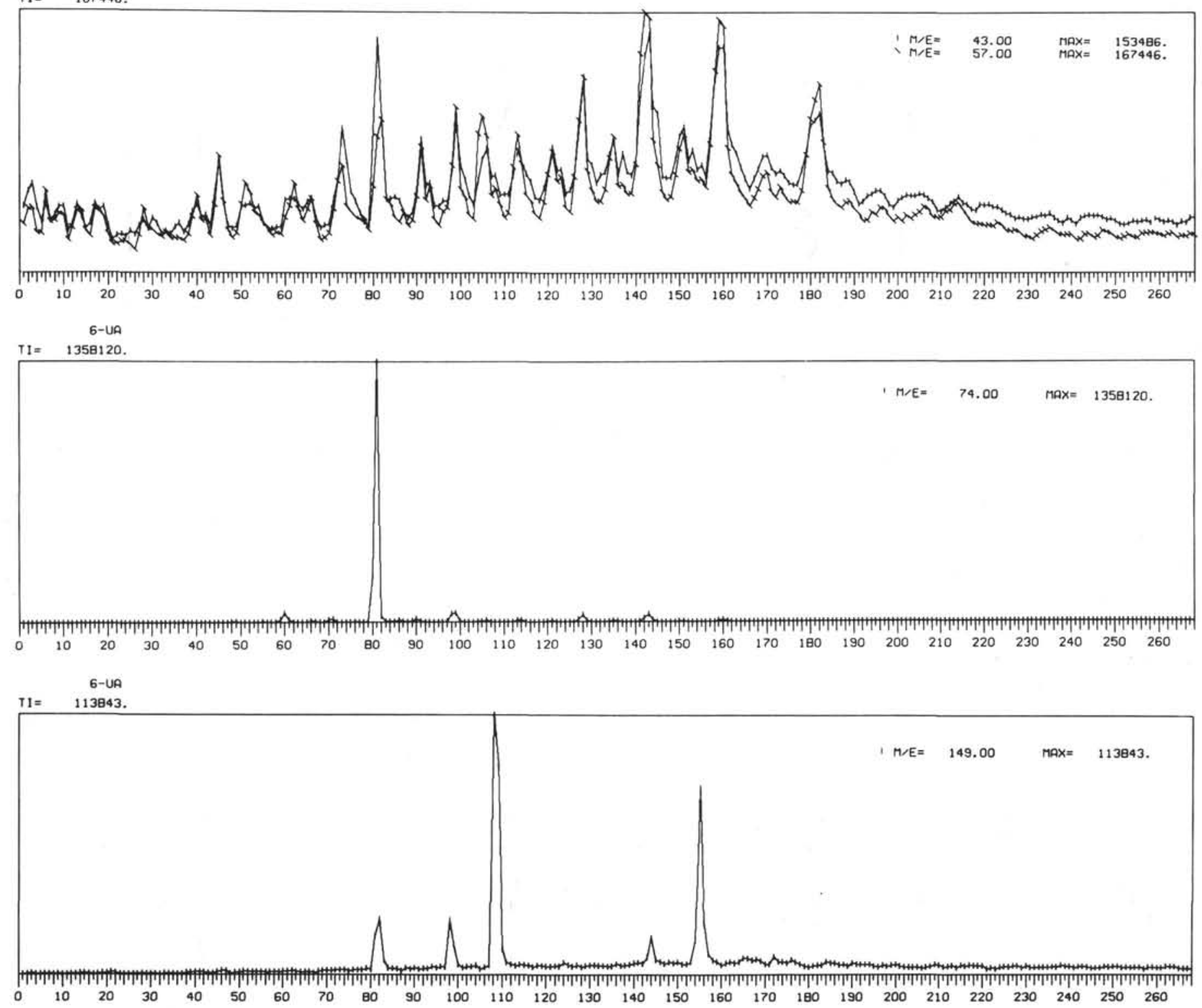

Figure 15. GC/MS data for the normal fraction (heptane soluble) from the exhaustive extract of Sample 147B-1-4 (6 m below sea bed). GC conditions as cited in Figure 2. (a) total ionization sum plot; (b) m/e 43 and m/e 57 sum plot; (c) m/e 74 sum plot; (d) m/e 149 sum plot. 

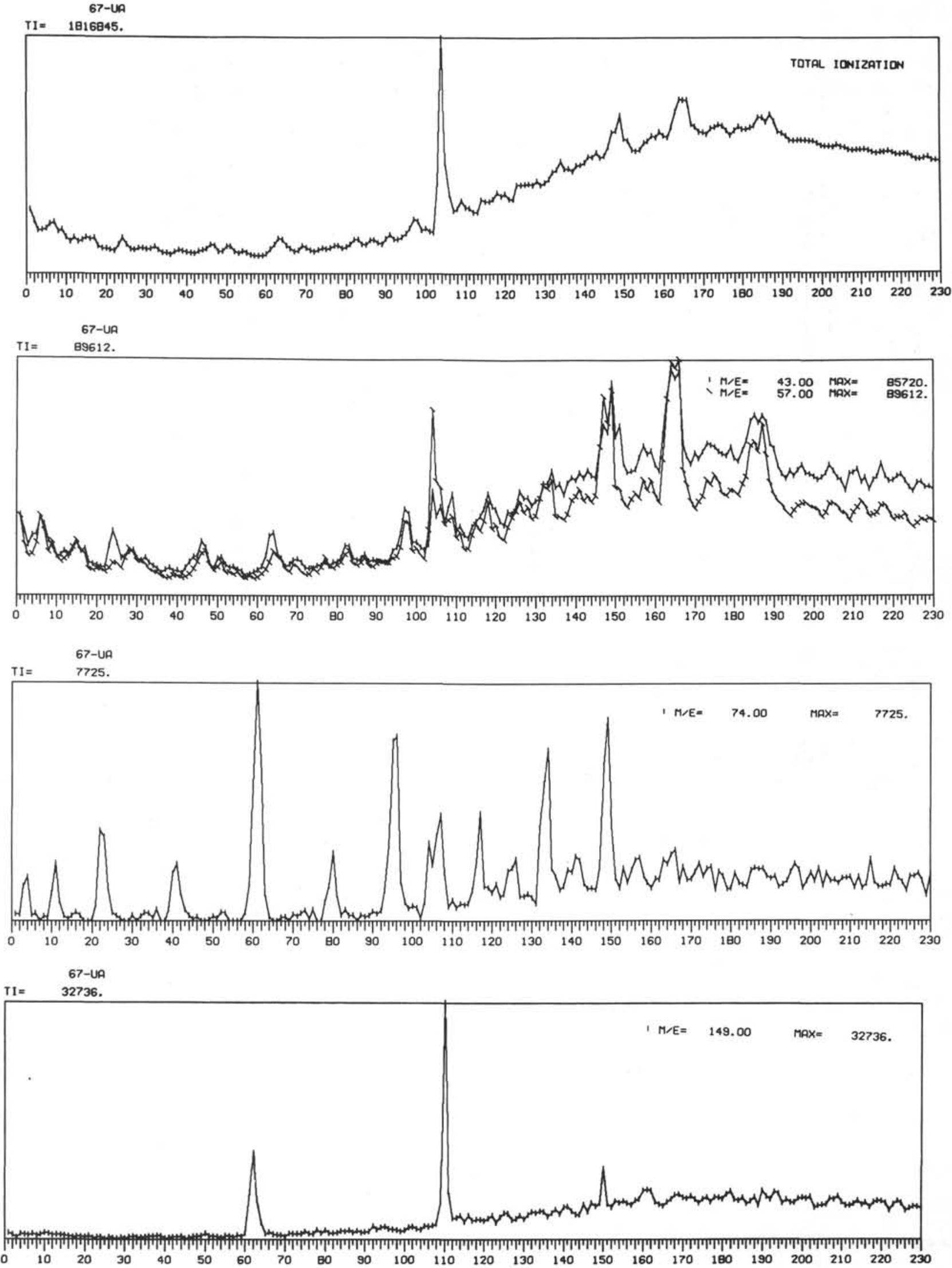

Figure 16. GC/MS data for the normal fraction (heptane soluble) from the exhaustive extract of Sample 147B-7-4 $(67 \mathrm{~m}$ below sea bed). GC conditions as cited in Figure 2. (a) total ionization sum plot; (b) $\mathrm{m} / \mathrm{e} 43$ and $\mathrm{m} / \mathrm{e} 57$ sum plot; (c) m/e 74 sum plot; (d) m/e 149 sum plot. 

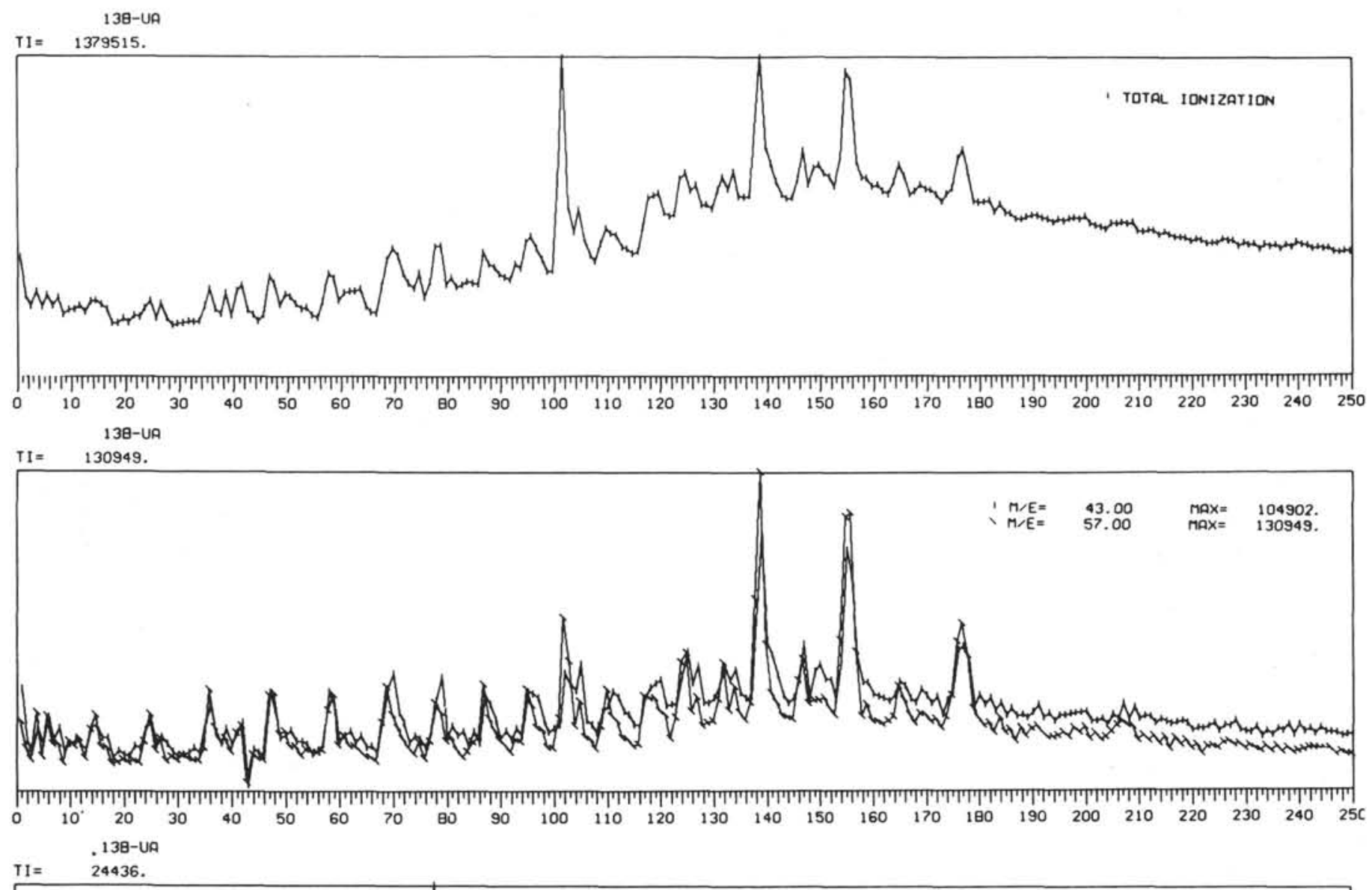

$\mathrm{T} I=24436$

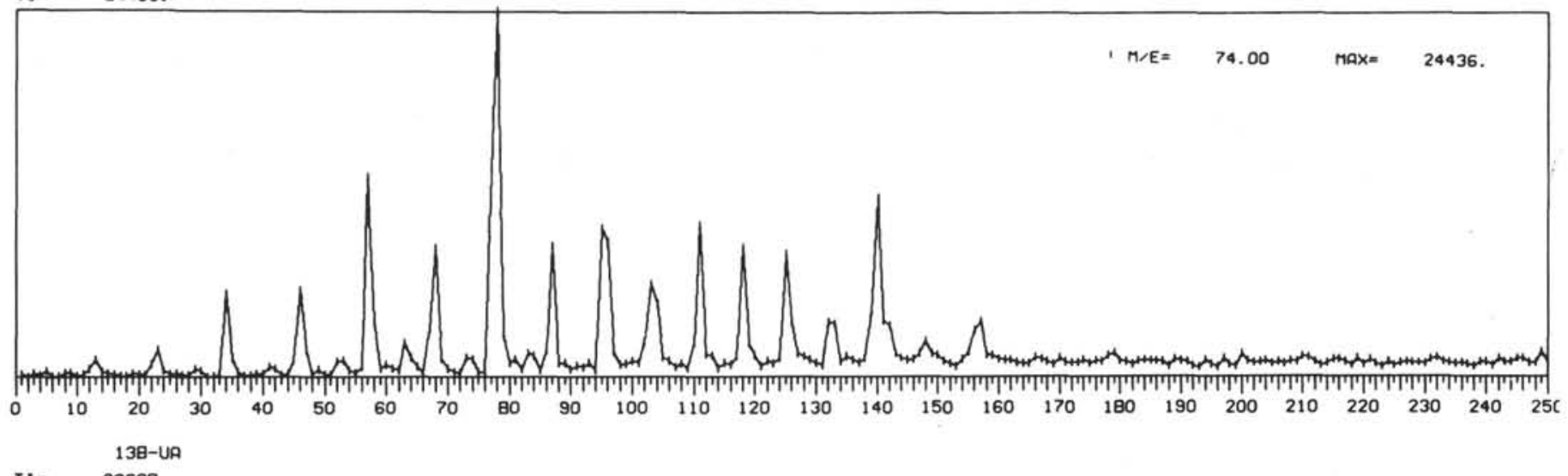

$\mathrm{TI}=2260 \mathrm{\theta}$.

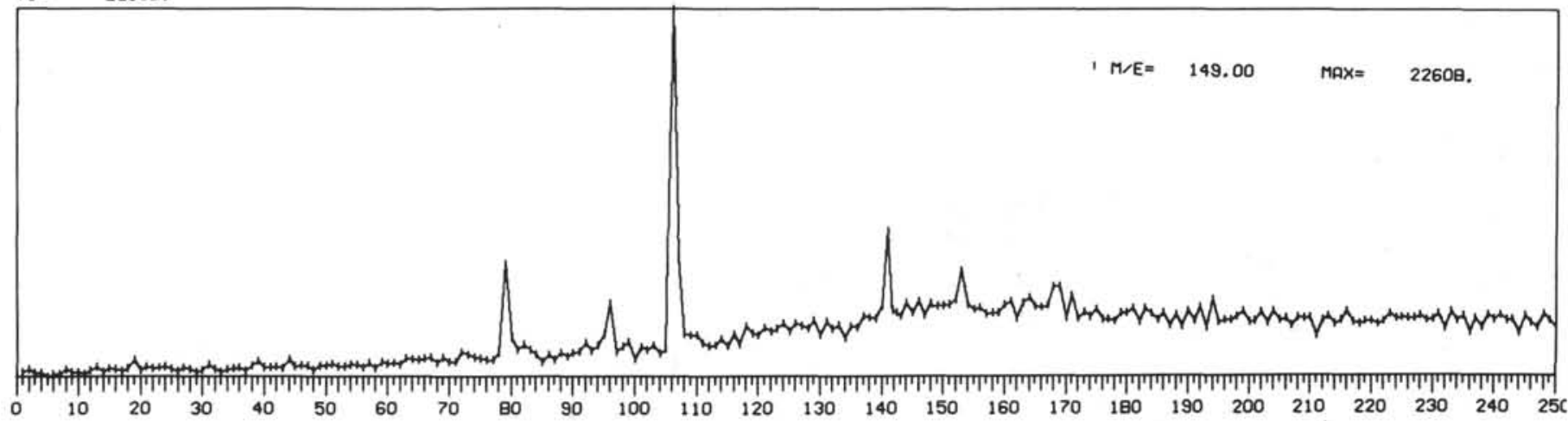

Figure 17. GC/MS data for the normal fraction (heptane soluble) from the exhaustive extract of Sample $147 \mathrm{C}-3-1^{+}(138 \mathrm{~m}$ below sea bed). GC conditions as cited in Figure 2. (a) total ionization sum plot; (b) $\mathrm{m} / \mathrm{e} 43$ and $\mathrm{m} / \mathrm{e} 57 \mathrm{sum}$ plot; (c) $\mathrm{m} / \mathrm{e}$ 74 sum plot; (d) m/e 149 sum plot. 
TABLE 5

Major Components of the Normal Fraction (Urea Adducted) from the Total Extract (Heptane Soluble) of Sample 147B-1-4 (6 m Below Sea Bed) as Determined by GC/MS

\begin{tabular}{|c|c|c|c|}
\hline \multirow{2}{*}{$\begin{array}{l}\text { Spectrum } \\
\text { Scan No.a }\end{array}$} & \multirow{2}{*}{$\begin{array}{l}\text { Compound Name } \\
\text { norphy tene }\end{array}$} & \multicolumn{2}{|c|}{$\begin{array}{l}\text { Composition and } \\
\text { Molecular Weight }\end{array}$} \\
\hline & & $\mathrm{C}_{19} \mathrm{H}_{38}$ & 266 \\
\hline 52 & $n$-octadecane & $\mathrm{C}_{18} \mathrm{H}_{38}$ & 254 \\
\hline 60 & methyl myristate & $\mathrm{C}_{15} \mathrm{H}_{30} \mathrm{O}_{2}$ & 242 \\
\hline \multirow[t]{2}{*}{66} & methyl pentadecanoate & $\mathrm{C}_{16} \mathrm{H}_{32} \mathrm{O}_{2}$ & 256 \\
\hline & phytadiene & $\mathrm{C}_{20} \mathrm{H}_{38}$ & 278 \\
\hline 73 & $n$-eicosane & $\mathrm{C}_{20} \mathrm{H}_{42}$ & 282 \\
\hline 81 & methyl palmitate & $\mathrm{C}_{17} \mathrm{H}_{34} \mathrm{O}_{2}$ & 270 \\
\hline 82 & $n$-heneicosane & $\mathrm{C}_{21} \mathrm{H}_{44}$ & 296 \\
\hline \multirow[t]{2}{*}{90} & methyl margarate & $\mathrm{C}_{18} \mathrm{H}_{36} \mathrm{O}_{2}$ & 284 \\
\hline & docosene & $\mathrm{C}_{22} \mathrm{H}_{44}$ & 308 \\
\hline 91 & n-docosane & $\mathrm{C}_{22} \mathrm{H}_{46}$ & 310 \\
\hline \multirow[t]{2}{*}{99} & methyl stearate & $\mathrm{C}_{19} \mathrm{H}_{38} \mathrm{O}_{2}$ & 298 \\
\hline & $n$-tricosane & $\mathrm{C}_{23} \mathrm{H}_{48}$ & 324 \\
\hline $104-105$ & dibutyl azelate ${ }^{\mathrm{b}}$ & $\mathrm{C}_{17} \mathrm{H}_{32} \mathrm{O}_{4}$ & 300 \\
\hline 108 & dioctyl phthalate ${ }^{c}$ & $\mathrm{C}_{24} \mathrm{H}_{38} \mathrm{O}_{4}$ & 390 \\
\hline 112 & $n$-pentacosane & $\mathrm{C}_{25} \mathrm{H}_{52}$ & 352 \\
\hline \multirow[t]{2}{*}{113} & $n$-pentacosane & $\mathrm{C}_{25} \mathrm{H}_{52}$ & 352 \\
\hline & methyl arachidate & $\mathrm{C}_{21} \mathrm{H}_{42} \mathrm{O}_{2}$ & 326 \\
\hline 120 & methyl heneicosanoate & $\mathrm{C}_{22} \mathrm{H}_{44} \mathrm{O}_{2}$ & 340 \\
\hline \multirow[t]{2}{*}{128} & $n$-heptacosane & $\mathrm{C}_{27} \mathrm{H}_{56}$ & 380 \\
\hline & methyl behenate & $\mathrm{C}_{23} \mathrm{H}_{46} \mathrm{O}_{2}$ & 354 \\
\hline \multirow[t]{2}{*}{143} & $n$-nonacosane & $\mathrm{C}_{29} \mathrm{H}_{60}$ & 408 \\
\hline & methyl lignocerate & $\mathrm{C}_{25} \mathrm{H}_{50} \mathrm{O}_{2}$ & 382 \\
\hline \multirow[t]{2}{*}{150} & methyl pentacosanoate & $\mathrm{C}_{26} \mathrm{H}_{52} \mathrm{O}_{2}$ & 396 \\
\hline & triacontene & $\mathrm{C}_{30} \mathrm{H}_{60}$ & 420 \\
\hline 155 & didecyl phthalate ${ }^{\mathrm{c}}$ & $\mathrm{C}_{28} \mathrm{H}_{46} \mathrm{O}_{4}$ & 466 \\
\hline 159 & methyl cerotate & $\mathrm{C}_{27} \mathrm{H}_{54} \mathrm{O}_{2}$ & 410 \\
\hline 181 & $n$-tritriacontane & $\mathrm{C}_{33}{ }^{\mathrm{H}_{68}}$ & 464 \\
\hline 182 & methyl heptacosanoate & $\mathrm{C}_{28} \mathrm{H}_{56} \mathrm{O}_{2}$ & 424 \\
\hline
\end{tabular}

${ }^{\mathrm{a}}$ See Figure 15a.

${ }^{\mathrm{b}}$ Probably core tube contamination.

${ }^{\mathrm{c}}$ Probably bagging contamination.

below the sea bed in the Black Sea (Simoneit, in press). The 6-meter sample from the Cariaco Trench (Site 147) was also deposited under anoxic conditions approximately $10^{4} \mathrm{y}$ B.P. This anoxic marine environment, although partially and periodically interrupted by the ice age (Adam, 1971), has enhanced the preservation of labile organic matter such as these olefins (Richards, 1970). It appears that zooplankton are the major source organisms for these phytadienes and norphytenes (Blumer and Thomas, 1965a and b). The marked decrease of these compounds with depth of burial indicates that diagenesis is taking place. Assuming uniform source conditions throughout the sediment sequence, the increase in the phytane and pristane concentration does not correspond to the phytadiene and norphytene decrease. This indicates that a portion of these olefins has been incorporated in the kerogen matrix as discussed above. Blumer and Snyder (1965) also proposed such a reduction of phytadienes to phytane. Further work is in progress to assess the significance and exact structures of these diagenetic markers.

The alkanes, $\mathrm{C}_{n} \mathrm{H}_{2 n+2}$, in all three samples ranged from approximately $n=18$ to 33 with an odd/even predominance. The corresponding alkenes (mainly $\mathrm{C}_{n} \mathrm{H}_{2 n}$ ) were present in lower amounts and decreased in overall concentration with sample depth. This distribution pattern correlates well with various samples from Legs 5 through 9 (Simoneit and Burlingame, 1971a and b, 1972a and b, Legs 10 through 13 (Simoneit et al., 1972, 1973, in press, and the Black Sea (Simoneit, in press). The second maximum $\left(\sim \mathrm{C}_{29}\right)$ in the bimodal distribution of the alkanes indicates some influx of higher plant detritus into the basin.

Steroidal compounds were found in all three samples, whereas triterpenoidal compounds were found in minor amounts in the samples from the 67-meter and 138-meter levels. The preliminary results indicate that the extent of reduction increases with the age of the sediment, i.e., sterols are reduced to steranes. A similar trend was observed for the steroid compounds in a sediment sequence from a residual Pleistocene lake (Henderson et al., 1972). The major sterols detected are probably cholesterol, ergosterol, and $\beta$-sitosterol and occur mainly in the 6-meter sample. The major steranes found are probably cholestane and stigmastane, with some stigmastene and cholestene, occurring mainly in the 67-meter and 138-meter samples. In the high resolution mass spectrometric data for these samples, a peak of composition $\mathrm{C}_{29} \mathrm{H}_{50} \mathrm{O}_{2}$, a possible sterol, was detected. Since this compound would not be expected to elute from a gas chromatographic column without prior conversion to a volatile derivative, it was not detected in the GC/MS data.

The minor amounts of pentacyclic triterpanes detected corroborate a partial influx of terrigenous plant material as indicated above. The major species detected has a molecular weight of 412 and could possibly be either lupane or oleanane derived from lupeol or the amyrins, both of which are present in the latex of tropical rubber trees.

Further work is planned to isolate, separate, and elucidate the absolute structures of the isoprenoidal, steroidal, and triterpenoidal compounds in this sediment sequence. The enhanced preservation of labile organic matter arising from the anoxic marine environment suggests that such studies would contribute significantly to gaining detailed insight into diagnetic processes occurring in such sediments. 


\section{ACKNOWLEDGMENTS}

We thank Mrs. Ellen Scott for assistance with GC/MS, Miss Rosalynd Jackson for assistance with high resolution mass spectrometry, and Mr. Cary Wong for data reduction. The financial support from the Oceanography Section of the National Science Foundation (NSF Grant GA-24214) is gratefully acknowledged.

TABLE 6

Major Components of the Normal Fraction (Urea Adducted) from the Total Extract (Heptane Soluble) of Sample 147B-7-4 ( $67 \mathrm{~m}$ Below Sea Bed) as Determined by GC/MS

\begin{tabular}{|c|c|c|c|}
\hline $\begin{array}{l}\text { Spectrum } \\
\text { Scan No, }\end{array}$ & Compound Name & $\begin{array}{l}\text { Composition } \\
\text { Molecular W }\end{array}$ & $\begin{array}{l}\text { and } \\
\text { eight }\end{array}$ \\
\hline 7 & unknown & & 238 \\
\hline 24 & methyl my ristate & $\mathrm{C}_{15} \mathrm{H}_{30} \mathrm{O}_{2}$ & 242 \\
\hline 46 & octadecadiene & $\mathrm{C}_{18} \mathrm{H}_{34}$ & 250 \\
\hline 51 & eicosene & $\mathrm{C}_{20} \mathrm{H}_{40}$ & 280 \\
\hline 61 & methyl palmitate & $\mathrm{C}_{17} \mathrm{H}_{34} \mathrm{O}_{2}$ & 270 \\
\hline & dibutyl phthalate ${ }^{b}$ & $\mathrm{C}_{24} \mathrm{H}_{22} \mathrm{O}_{4}$ & 278 \\
\hline 63 & unknown & & 254 \\
\hline 69 & $n$-heneicosane & $\mathrm{C}_{21} \mathrm{H}_{44}$ & 296 \\
\hline & heneicosene & $\mathrm{C}_{21} \mathrm{H}_{42}$ & 294 \\
\hline 82 & $n$-docosane & $\mathrm{C}_{22} \mathrm{H}_{46}$ & 310 \\
\hline 95 & methyl stearate & $\mathrm{C}_{19} \mathrm{H}_{38} \mathrm{O}_{2}$ & 298 \\
\hline 96 & $n$-tricosane & $\mathrm{C}_{23} \mathrm{H}_{48}$ & 324 \\
\hline $103-104$ & dibutyl azelate ${ }^{c}$ & $\mathrm{C}_{17} \mathrm{H}_{32} \mathrm{O}_{4}$ & 300 \\
\hline 109 & tetracosene & $\mathrm{C}_{24} \mathrm{H}_{48}$ & 336 \\
\hline 110 & dioctyl phthalate ${ }^{b}$ & $\mathrm{C}_{24} \mathrm{H}_{38} \mathrm{O}_{4}$ & 390 \\
\hline 114 & dibutyl sebacate ${ }^{c}$ & $\mathrm{C}_{18} \mathrm{H}_{34} \mathrm{O}_{4}$ & 314 \\
\hline 118 & $n$-pentacosane & $\mathrm{C}_{25} \mathrm{H}_{52}$ & 352 \\
\hline 123 & dibutyl hendecanedioate ${ }^{c}$ & $\mathrm{C}_{19} \mathrm{H}_{36} \mathrm{O}_{4}$ & 328 \\
\hline 128 & hexacosene & $\mathrm{C}_{26} \mathrm{H}_{52}$ & 364 \\
\hline 134 & $n$-heptacosane & $\mathrm{C}_{27} \mathrm{H}_{56}$ & 380 \\
\hline & methyl behenate & $\mathrm{C}_{23} \mathrm{H}_{46} \mathrm{O}_{2}$ & 354 \\
\hline 142 & octacosene & $\mathrm{C}_{28} \mathrm{H}_{56}$ & 392 \\
\hline 147 & nonacosene & $\mathrm{C}_{29} \mathrm{H}_{58}$ & 406 \\
\hline 149 & $n$-nonacosane & $\mathrm{C}_{29} \mathrm{H}_{60}$ & 408 \\
\hline & methyl lignocerate & $\mathrm{C}_{25} \mathrm{H}_{50} \mathrm{O}_{2}$ & 382 \\
\hline 157 & $n$-triacontane & $\mathrm{C}_{30} \mathrm{H}_{62}$ & 422 \\
\hline 164 & $n$-hentriacontane & $\mathrm{C}_{31} \mathrm{H}_{64}$ & 436 \\
\hline 172 & dotriacontene & $\mathrm{C}_{32} \mathrm{H}_{64}$ & 448 \\
\hline 184 & $n$-tritriacontane & $\mathrm{C}_{33} \mathrm{H}_{68}$ & 464 \\
\hline
\end{tabular}

${ }^{\mathrm{a}}$ See Figure 16a.

b Probably bagging contamination.

${ }^{c}$ Probably core tube contamination.

\section{REFERENCES}

Abelson, P. H. and Hare, P. E., 1970. Uptake of amino acids by kerogen. Carnegie Inst. Wash. Y. Book 68, 197.

Adam, D. P., 1971. Paleoclimatic significance of the stagnation of the Cariaco Trench. Nature. 232, 469.

Arpino, P. and Ourisson, G., 1971. Interactions between rock and organic matter. Esterification and transesterification induced in sediments by methanol and ethanol. Anal. Chem. 43, 1656.

Blumer, N. and Snyder, W. D., 1965. Isoprenoid hydrocarbons in recent sediments: presence of pristane and probable absence of phytane. Science. 150, 1588.

Blumer, M. and Thomas, D. W., 1965a. Phytadienes in zooplankton. Science. 147, 1148.

Burlingame, A. L., 1970. Developments and applications of real-time high resolution mass spectrometry. Presented at the Intern. Conf. on Mass Spectroscopy, Kyoto, Sept. 8-12, 1969. Recent Developments in Mass Spectroscopy. K. Ogata and T. Hayakawa (Eds.), Tokyo (Univ. Tokyo Press), 104.

Burlingame, A. L. and Simoneit, B. R., 1968. Isoprenoid fatty acids isolated from the kerogen matrix of the Green River Formation (Eocene). Science. 160, 531.

Burlingame, A. L. and Simoneit, B. R., 1969. High resolution mass spectrometry of Green River Formation kerogen oxidations. Nature. 222, 741.

Burlingame, A. L. and Smith, D. H., 1968. Automated heteroatomic plotting as an aid to the presentation and interpretation of high resolution mass spectral data. Tetrahedron. 24, 5749.

Burlingame, A. L., Smith, D. H., Merren, T. O. and Olsen, R. W., 1970. Real-time high resolution mass spectrometry. Computers in Analytical Chemistry. In Progress in Analytical Chemistry, C. H. Orr and J. Norris (Eds.), New York (Plenum Press) 4, 17.

Edgar, N. T. et al., 1971. Leg 15 Deep Sea Drilling Project, Geotimes, 16 (4), 12.

Han, J. C-Y., 1970. Chemical studies of terrestrial and extraterrestrial life. Ph.D. Dissertation, Univ. California, Berkelev. 182

Henderson, W., Reed, W. E. and Steel, G., 1972. The origin and incorporation of organic modules in sediments as elucidated by studies of the sedimentary sequence from a residual Pleistocene lake. In Advances in Organic Geochemistry 1971. H. R. von Gaertner and H. Wehner (Eds.), Braunschweig (Pergamon-Vieweg). 335.

Meyers, P. A. and Quinn, J. G., 1971. Fatty acid-clay mineral association in artificial and natural sea water solutions. Geochim. Cosmochim. Acta. 35, 628.

Parker, P. L., van Baalen, C. and Maurer, L., 1967. Fatty acids in eleven species of blue-green algae; geochemical significance. Science. 155, 707.

Richards, F. A., 1970. The enhanced preservation of organic matter in anoxic marine environments. In Symposium on Organic Matter in Natural Waters. D. W. Hood (Ed.), Univ. Alaska (Inst. Marine Sci.). 399.

Richards, F. A. and Vaccaro, R. F., 1956. The Cariaco Trench, an anaerobic basin in the Caribbean Sea. Deep-Sea Res. 3, 214.

Simoneit, B. R., in press. Organic analyses of Black Sea cores. In The Black Sea: Geology, Chemistry and Biology Am. Assoc. Petrol. Geologists Mem.

Simoneit, B. R. and Burlingame, A. L., 1971a. Some preliminary results on the higher weight hydrocarbons and fatty acids in the Deep Sea Drilling Project cores, legs 5-7. In Winterer, E. L., Riedel, W. R. et al., 1971. Initial Reports of the Deep Sea Drilling Project, Volume 
VII. Washington (U S. Government Printing Office) 889.

1971 b. Further preliminary results on the higher weight hydrocarbons and fatty acids in the Deep Sea Drilling Project cores, legs 5-8. In Tracey, J. I. Jr., Sutton, G. H., et al., 1970. Initial Reports of the Deep Sea Drilling Project, Volume VIII. Washington (U.S. Government Printing Office) 873 .

1972a. Further preliminary Results on the higher weight hydrocarbons and fatty acids in the Deep Sea Drilling Project cores, leg 9. In Hays, J. D. et al., 1972. Initial Reports of the Deep Sea Drilling Project, Washington (U.S. Government Printing Office). 859.

, 1972b. Preliminary organic analyses of the Deep Sea Drilling Project (JOIDES) cores, legs V-IX. In Advances in Organic Geochemistry 1971. H. R. Von Gaertner and H. Wehner (Eds.). Braunschweig (PergamonVieweg). 189.

Simoneit, B. R., Scott, E. S. Howells, W. G. and Burlingame, A. L., 1972. Preliminary organic analyses of the Deep Sea Drilling Project cores from leg 11. In Ewing, J. I., Hollister, C. D. et al., 1972. Initial Reports of the Deep Sea Drilling Project, Volume XI. Washington (U.S. Government Printing Office), 1013.

Simoneit, B. R., Scott, E. S. and Burlingame, A. L., 1973. Preliminary organic analyses of the Deep Sea Drilling Project cores, leg 10. In Worzel, J. L., Bryant, W. et al. Initial Reports of the Deep Sea Drilling Project, Volume X. Washington (U. S. Government Printing Office), 625.

Simoneit, B. R., and Burlingame, A. L., in press. Preliminary organic analyses of Deep Sea Drilling Project cores from legs 12 and 13. In R. von Huene, L. D. Kulm, et al. Initial Reports of the Deep Sea Drilling Project, Volume XVIII. Washington (U. S. Government Printing Office).

Smith, D. H., 1972. A compound classifier based on computer analysis of low resolution mass spectral data. Geochemical and environmental applications. Anal. Chem. 44, 536.

Smith, D. H., Olsen, R. W., Walls, F. C. and Burlingame, A. L., 1971. Real-time organic mass spectrometry: LOGOS - a generalized laboratory system for high and low resolution, GC/MS and closed-loop applications. Anal. Chem. 43, 1796.

Wehmiller, J. F. and Hare, P. E., 1972. Amino acid content of some samples from the Deep Sea Drilling Program. In Hays, J. D. et al., 1972. Initial Reports of the Deep Sea Drilling Project, Volume IX. Washington (U. S. Government Printing Office). 903.

TABLE 7

Major Components of the Normal Fraction (Urea Adducted) from the Total Extract (Heptane Soluble) of Sample 147C-3-1+ (138 $\mathrm{m}$ Below Sea Bed) as Determined by GC/MS

\begin{tabular}{cllr}
\hline $\begin{array}{c}\text { Spectrum } \\
\text { Scan No. }\end{array}$ & Compound Name & \multicolumn{2}{c}{$\begin{array}{l}\text { Composition and } \\
\text { Molecular Weight }\end{array}$} \\
\hline 14 & $n$-pentadecane & $\mathrm{C}_{15} \mathrm{H}_{32}$ & 212 \\
25 & $n$-hexadecane & $\mathrm{C}_{16} \mathrm{H}_{34}$ & 226 \\
36 & $n$-heptadecane & $\mathrm{C}_{17} \mathrm{H}_{36}$ & 240 \\
47 & $n$-octadecane & $\mathrm{C}_{18} \mathrm{H}_{38}$ & 254
\end{tabular}

TABLE 7 - Continued

\begin{tabular}{|c|c|c|c|}
\hline \multirow{2}{*}{$\begin{array}{c}\text { Spectrum } \\
\text { Scan No. }\end{array}$} & \multirow{2}{*}{$\begin{array}{l}\text { Compound Name } \\
\text { methyl myristate }\end{array}$} & \multicolumn{2}{|c|}{$\begin{array}{l}\text { Composition and } \\
\text { Molecular Weight }\end{array}$} \\
\hline & & $\mathrm{C}_{15} \mathrm{H}_{30} \mathrm{O}_{2}$ & 242 \\
\hline 58 & $n$-nonadecane & $\mathrm{C}_{19} \mathrm{H}_{40}$ & 268 \\
\hline 68 & methyl pentadecanoate & $\mathrm{C}_{16} \mathrm{H}_{32} \mathrm{O}_{2}$ & 256 \\
\hline \multirow[t]{2}{*}{69} & $n$-eicosane & $\mathrm{C}_{20} \mathrm{H}_{42}$ & 282 \\
\hline & eicosene & $\mathrm{C}_{20} \mathrm{H}_{40}$ & 280 \\
\hline 77 & methyl palmitate & $\mathrm{C}_{17} \mathrm{H}_{34} \mathrm{O}_{2}$ & 270 \\
\hline \multirow[t]{2}{*}{78} & $n$-heneicosane & $\mathrm{C}_{21} \mathrm{H}_{44}$ & 296 \\
\hline & methyl palmitate & $\mathrm{C}_{17} \mathrm{H}_{34} \mathrm{O}_{2}$ & 270 \\
\hline 79 & dibutyl phthalate ${ }^{b}$ & $\mathrm{C}_{16} \mathrm{H}_{22} \mathrm{O}_{4}$ & 278 \\
\hline 87 & $n$-docosane & $\mathrm{C}_{22} \mathrm{H}_{46}$ & 310 \\
\hline 88 & methyl margarate & $\mathrm{C}_{18} \mathrm{H}_{36} \mathrm{O}_{2}$ & 284 \\
\hline 95 & $n$-tricosane & $\mathrm{C}_{23} \mathrm{H}_{48}$ & 324 \\
\hline 96 & methyl stearate & $\mathrm{C}_{19} \mathrm{H}_{38} \mathrm{O}_{2}$ & 298 \\
\hline 102 & dibutyl azelate ${ }^{c}$ & $\mathrm{C}_{17} \mathrm{H}_{32} \mathrm{O}_{4}$ & 300 \\
\hline \multirow[t]{2}{*}{105} & $n$-tetracosane & $\mathrm{C}_{24} \mathrm{H}_{50}$ & 338 \\
\hline & methyl nonadecanoate & $\mathrm{C}_{20} \mathrm{H}_{40^{2}}$ & 312 \\
\hline \multirow[t]{3}{*}{106} & $n$-tetracosane & $\mathrm{C}_{24} \mathrm{H}_{50}$ & 338 \\
\hline & pentacosene & $\mathrm{C}_{25} \mathrm{H}_{50}$ & 350 \\
\hline & dioctyl phthalate ${ }^{b}$ & $\mathrm{C}_{24} \mathrm{H}_{38} \mathrm{O}_{4}$ & 390 \\
\hline \multirow[t]{2}{*}{110} & $n$-pentacosane & $\mathrm{C}_{25} \mathrm{H}_{52}$ & 352 \\
\hline & methyl arachidate & $\mathrm{C}_{21} \mathrm{H}_{42} \mathrm{O}_{2}$ & 326 \\
\hline \multirow[t]{2}{*}{119} & $n$-hexacosane & $\mathrm{C}_{26} \mathrm{H}_{54}$ & 366 \\
\hline & methyl heneicosanoate & $\mathrm{C}_{22} \mathrm{H}_{44} \mathrm{O}_{2}$ & 340 \\
\hline \multirow[t]{2}{*}{125} & $n$-heptacosane & $\mathrm{C}_{27} \mathrm{H}_{56}$ & 380 \\
\hline & methyl behenate & $\mathrm{C}_{23} \mathrm{H}_{46} \mathrm{O}_{2}$ & 354 \\
\hline \multirow[t]{2}{*}{132} & $n$-octacosane & $\mathrm{C}_{28} \mathrm{H}_{58}$ & 394 \\
\hline & methyl tricosanoate & $\mathrm{C}_{24} \mathrm{H}_{48} \mathrm{O}_{2}$ & 368 \\
\hline \multirow[t]{2}{*}{139} & $n$-nonacosane & $\mathrm{C}_{29} \mathrm{H}_{60}$ & 408 \\
\hline & methyl lignocerate & $\mathrm{C}_{25} \mathrm{H}_{50} \mathrm{O}_{2}$ & 382 \\
\hline 147 & $n$-tricontane & $\mathrm{C}_{30} \mathrm{H}_{62}$ & 422 \\
\hline \multirow[t]{2}{*}{155} & $n$-hentriacontane & $\mathrm{C}_{31} \mathrm{H}_{64}$ & 436 \\
\hline & hen triacontane & $\mathrm{C}_{31} \mathrm{H}_{62}$ & 434 \\
\hline \multirow[t]{2}{*}{157} & $n$-hentriacontane & $\mathrm{C}_{31} \mathrm{H}_{64}$ & 436 \\
\hline & methyl cerotate & $\mathrm{C}_{27} \mathrm{H}_{54} \mathrm{O}_{2}$ & 410 \\
\hline 165 & $n$-dotriacontane & $\mathrm{C}_{32} \mathrm{H}_{66}$ & 450 \\
\hline 177 & $n$-tritriacontane & $\mathrm{C}_{33} \mathrm{H}_{68}$ & 464 \\
\hline
\end{tabular}


TABLE 8

Major Components of the Branched-Cyclic Portion (Urea Non-adducted) from the Heptane Soluble Fraction of the Samples from Site 147, as Determined by GC/MS

\begin{tabular}{|c|c|c|c|c|c|}
\hline \multirow[b]{2}{*}{ Compound Name } & \multirow{2}{*}{\multicolumn{2}{|c|}{$\begin{array}{l}\text { Composition and } \\
\text { Molecular Weight }\end{array}$}} & \multicolumn{3}{|c|}{ Site 147 Samples ${ }^{a}$} \\
\hline & & & $6 \mathrm{~m}$ & $67 \mathrm{~m}$ & $138 \mathrm{~m}$ \\
\hline Undecene & $\mathrm{C}_{11} \mathrm{H}_{22}$ & 154 & + & + & +t \\
\hline iso-Undecane & $\mathrm{C}_{11} \mathrm{H}_{24}$ & 156 & tr. & + & + \\
\hline Tridecadiene & $\mathrm{C}_{13} \mathrm{H}_{24}$ & 180 & + & tr. & + \\
\hline Tridecene & $\mathrm{C}_{13} \mathrm{H}_{26}$ & 182 & + & + & + \\
\hline Diethyl phthalatea & $\mathrm{C}_{12} \mathrm{H}_{14} \mathrm{O}_{4}$ & 222 & tr. & tr. & tr. \\
\hline Tetradecene & $\mathrm{C}_{14} \mathrm{H}_{28}$ & 196 & + & + & + \\
\hline Pentadecadiene & $\mathrm{C}_{15} \mathrm{H}_{28}$ & 208 & ++ & + & + \\
\hline Pentadecene & $\mathrm{C}_{15} \mathrm{H}_{30}$ & 210 & + & + & $\cdot+$ \\
\hline $2,6,10$-trimethyl pentadecane & $\mathrm{C}_{18} \mathrm{H}_{38}$ & 254 & + & + & + \\
\hline Methyl my ristate & $\mathrm{C}_{15} \mathrm{H}_{30} \mathrm{O}_{2}$ & 242 & tr. & tr. & tr. \\
\hline Lauryl alcohol & $\mathrm{C}_{12} \mathrm{H}_{26} \mathrm{O}$ & 186 & n.d. & n.d. & tr. \\
\hline Pristene & $\mathrm{C}_{19} \mathrm{H}_{38}$ & 266 & +++ & +++ & ++ \\
\hline Pristane & $\mathrm{C}_{19} \mathrm{H}_{40}$ & 268 & ++ & + & ++ \\
\hline Methyl pentadecanoate & $\mathrm{C}_{16} \mathrm{H}_{32} \mathrm{O}_{2}$ & 256 & tr. & tr. & tr. \\
\hline Phytadiene & $\mathrm{C}_{20} \mathrm{H}_{38}$ & 278 & ++ & ++ & ++ \\
\hline Phy tene & $\mathrm{C}_{20} \mathrm{H}_{40}$ & 280 & +++ & +++ & +t+ \\
\hline Phy tane & $\mathrm{C}_{20} \mathrm{H}_{42}$ & 282 & +++ & +++ & +++ \\
\hline$n$-Nonadecane & $\mathrm{C}_{19} \mathrm{H}_{40}$ & 268 & tr. & + & + \\
\hline Methyl palmitate & $\mathrm{C}_{17} \mathrm{H}_{34} \mathrm{O}_{2}$ & 270 & ++ & + & + \\
\hline Dibutyl ph thalate ${ }^{b}$ & $\mathrm{C}_{16} \mathrm{H}_{22} \mathrm{O}_{4}$ & 278 & + & + & tr. \\
\hline Heneicosene & $\mathrm{C}_{21} \mathrm{H}_{42}$ & 294 & + & + & + \\
\hline Methyl margarate & $\mathrm{C}_{18} \mathrm{H}_{36} \mathrm{O}_{2}$ & 284 & + & tr. & n.d. \\
\hline$n$-heneicosane & $\mathrm{C}_{21} \mathrm{H}_{44}$ & 296 & + & + & + \\
\hline Dibutyl azelate ${ }^{c}$ & $\mathrm{C}_{17} \mathrm{H}_{32} \mathrm{O}_{4}$ & 300 & +++ & +++ & ++ \\
\hline Docosene & $\mathrm{C}_{22}{ }^{\mathrm{H} 44}$ & 308 & tr. & + & + \\
\hline iso-Docosane & $\mathrm{C}_{22} \mathrm{H}_{46}$ & 310 & + & tr. & n.d. \\
\hline Methyl stearate & $\mathrm{C}_{19} \mathrm{H}_{38} \mathrm{O}_{2}$ & 298 & + & + & + \\
\hline Dibutyl sebacate & $\mathrm{C}_{18} \mathrm{H}_{34} \mathrm{O}_{4}$ & 314 & tr. & tr. & tr. \\
\hline Tricosene & $\mathrm{C}_{23} \mathrm{H}_{46}$ & 322 & + & + & + \\
\hline
\end{tabular}

TABLE 8 - Continued

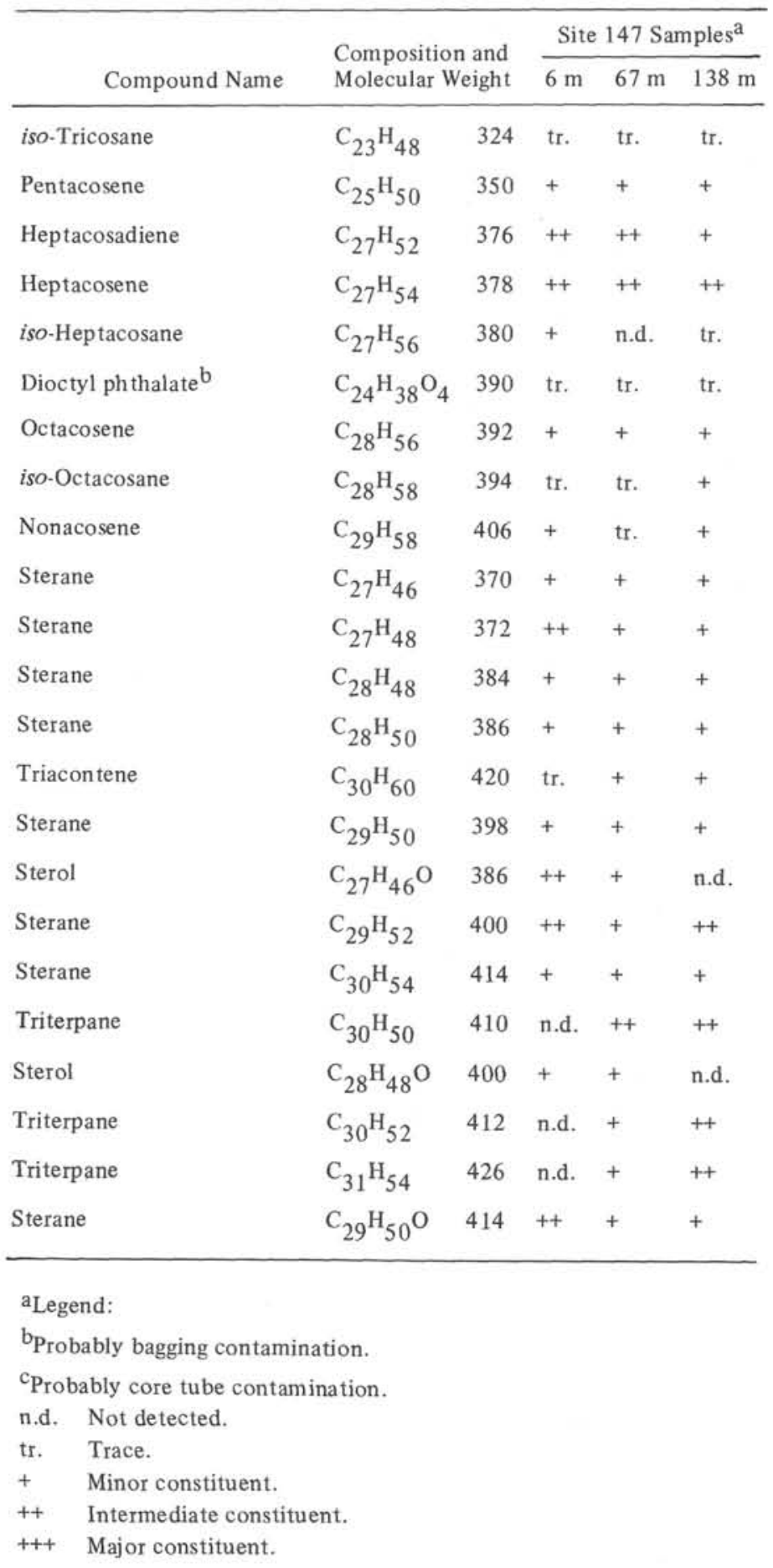




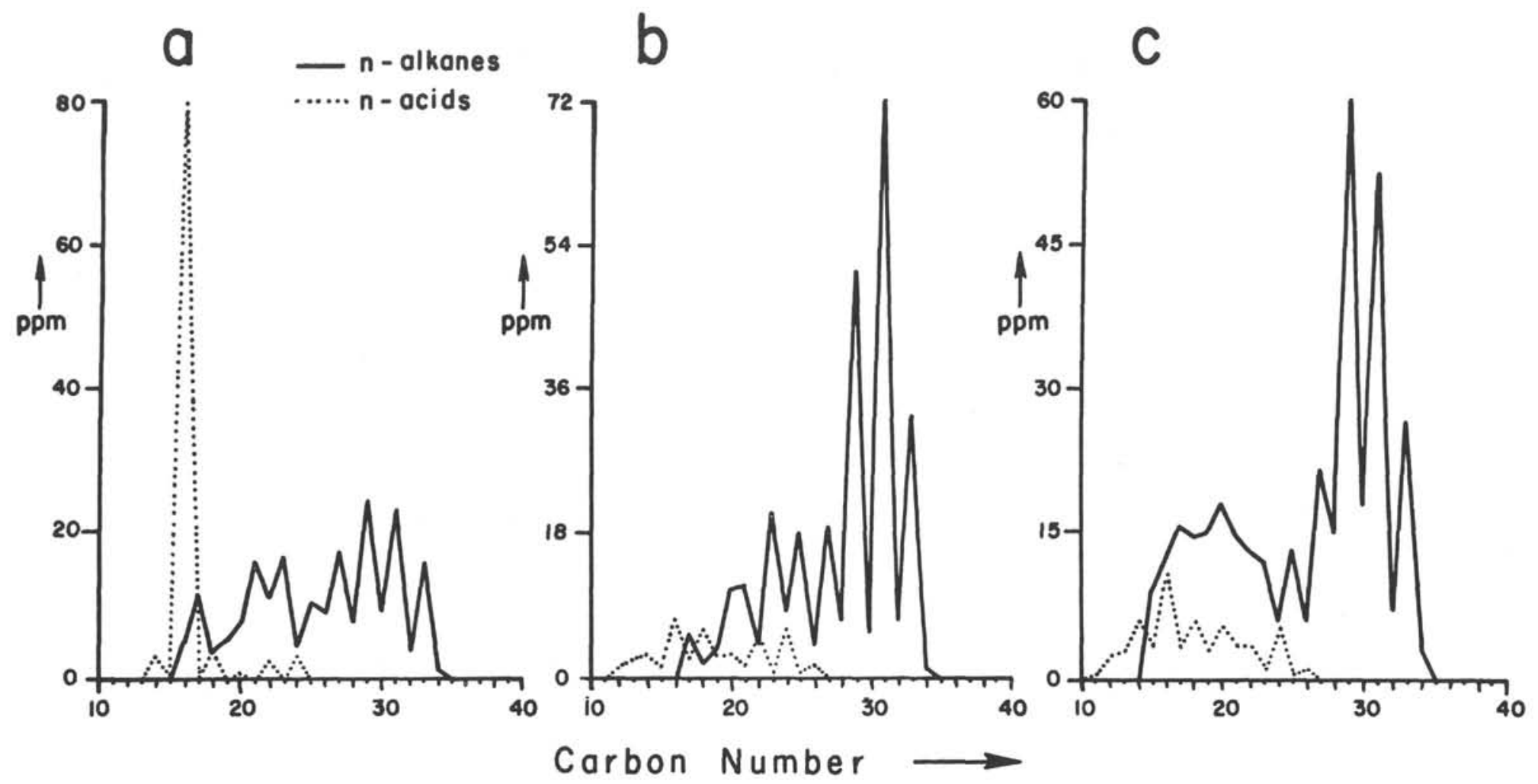

Figure 18. Concentration histograms (ppm of dry weight) of the n-alkanes and the normal acids for the heptane soluble organic matter in the samples from Site 147. (a) Sample 147B-1-4 (6 m), (b) Sample 147B-7-4 (67 m), (c) Sample 147C-3$1^{+}(138 \mathrm{~m})$. 